\title{
Detection of Thermal Changes Related to the 2011 Shinmoedake Volcano Activity, Japan: Spatiotemporal Variation of Singularity of MODIS Data after Discriminating False Changes Due to Cloud
}

\author{
Rika Tsutsumi $^{1,+}$, Katsumi Hattori ${ }^{1,2, * \mathbb{D}}$, Chie Yoshino ${ }^{1}$ and Nicola Genzano ${ }^{3}$ (D) \\ 1 Graduate School of Science, Chiba University, Chiba 263-8522, Japan; pf902u@gmail.com (R.T.); \\ chie@earth.s.chiba-u.ac.jp (C.Y.) \\ 2 Center for Environmental Remote Sensing, Chiba University, Chiba 263-8522, Japan \\ 3 School of Engineering, University of Basilicata, Potenza 85100, Italy; nicola.genzano@unibas.it \\ * Correspondence: khattori@faculty.chiba-u.jp \\ + Now working at salesforce.com, Inc., Tokyo 100-7012, Japan.
}

Received: 30 June 2020; Accepted: 12 August 2020; Published: 15 August 2020

\begin{abstract}
We proposed a cloud discrimination method applicable in Japan using MODIS nighttime data, monitored the singularity of the spatiotemporal correlation of surface temperature anomalies and investigated the possibility of detecting and monitoring lava activity in Shinmoedake. With the aim to detect lava eruption activity in 2011, nine years of data from 2003 to 2011 were analyzed. As a result, the first anomalous singularity in brightness temperature was detected on 26 January 2011. Moreover, the maximum value was detected on 30 January 2011. The values showed larger ones until early February 2011. When an anomalous singularity appeared, it was the only period with the magma-related volcanic activity for Shinmoedake over the analyzed period of nine years. The above facts indicate the effectiveness of the proposed singularity method to monitor the lava activity for Shinmoedake. Therefore, it is concluded that if cloud discrimination is realized with high accuracy, no spurious changes will come to arise, and no false detection of hotspots will be given.
\end{abstract}

Keywords: Shinmoedake; MODIS; singularity; cloud discrimination; brightness temperature; brightness temperature difference; volcanic lava activity; volcanic thermal anomaly

\section{Introduction}

There are many active volcanoes in the world and many volcano-related disasters have been reported. In order to reduce these natural disasters, monitoring of volcanic activity is essential. However, it is very difficult to monitor all volcanoes on the ground because of topological, geographical and economic difficulties. However, we can efficiently monitor global volcanic activities using satellite remote sensing techniques because a volcanic activity will cause an increase in surface temperature and satellite (whose sensor can observe the surface temperature) remote sensing can cover a large area on the surface at high frequency with continuity.

Therefore, various approaches (e.g., [1-17]) have been suggested to monitor volcanic activities using remote-sensing data collected in the Medium InfraRed (MIR) and Thermal InfraRed (TIR) spectral range, also by the new sensors, such as Advanced Himawari Imager (AHI) onboard HIMAWARI-8 satellite (e.g., [11]). For example, MODVOLC [2] and MIROVA [12] exploit data acquired by MODerate resolution Imaging Spectroradiometer (MODIS) to monitor active volcanoes at the global scale in an operative way, releasing products few hours after the MODIS acquisition. RST VOLC $_{\text {(Robust }}$ 
Satellite Technique to identify volcanic thermal anomalies) [13] by analyzing time series of satellite imagery collected by polar sensors like Advanced Very High Resolution Radiometer (AVHRR) and MODIS, as well as the geostationary sensor Spinning Enhanced Visible and InfraRed Imager (SEVIRI), has provided useful information on ongoing thermal activities of many active volcanoes around the world. HOTSAT [15], HOTVOLC [16] and AVHotRR [17], which also exploit the data collected by the MODIS sensor, are other approaches/systems currently used for the volcanoes activity investigations.

On the other hand, medium-high spatial resolution satellite sensors, such as Thematic Mapper (TM), Advanced Spaceborne Thermal Emission and Reflection Radiometer (ASTER), Operational Land Imager (OLI) and Multi-Spectral Instrument (MSI), which provide imagery also in the ShortWave InfraRed (SWIR) spectral range, have been demonstrated good ability to map lava flows (see for example [18-20]). To understand eruptive precursors and eruptive dynamics of volcanoes, the integration of multiparametric datasets of satellite and ground data can help better monitor volcanic hazards.

Regarding volcanic activity, considerable damage to human life is often associated with pyroclastic flows. Therefore, it is crucial to detect the possibility of pyroclastic flow in advance and contribute to disaster prevention and mitigation by identifying reliable heat sources of the lava dome and lava flow. Therefore, the satellite remote sensing is the key to accurately detect temperature anomalies (temperature increase) or hotspots associated with volcanic activity and lava eruption. Obstacles to this realization are the spatial and temporal resolution of the satellite's orbit, the cloud coverage over the targets and contamination by sunlight effects. Nighttime data are often used to detect temperature anomalies to avoid sunlight influences accurately, but nighttime cloud discrimination is generally difficult. Various attempts have been performed for cloud discrimination [9-16,18-24]. However, most of them are available to daytime data for which visible images can be used for verification, and nighttime data are not universally reported.

It is reported that volcanic eruption activity in Indonesia can be detected using the infrared sensor (MODIS) onboard satellite Aqua [9]. In their approach, cloud discrimination is an essential factor in monitoring the lava condition accurately. For example, in Indonesia in the tropics, the convection is rather simple, and the generated clouds are uniform (cumulonimbus). As a result, there is no seasonal change, such as the rainy season or the dry season, and it is simple. Using MODIS band $31(11 \mu \mathrm{m})$ and band $32(12 \mu \mathrm{m})$, cloud discrimination is available and established.

On the other hand, in Mt. Asama in Japan, the accuracy of lava activity monitoring is found to be inadequate because their cloud discrimination algorithm is too simple to be applied successfully in Japan. Therefore, the purpose of this study is to remove the cloud accurately and to develop an adequate algorithm continuously to detect thermal anomalies related to volcanic activities, especially lava activity in Japan. In this paper, the cloud discrimination algorithm is improved to investigate the spatiotemporal changes of MODIS data based on the singularity developed by Noguchi et al. [9]. In their approach, to detect only hotspots related to lava activities without faints, the developed algorithm investigates the difference temperature behavior between a target point and reference points, and we get the spatial difference of brightness temperature (S). The presence of clouds causes a large value of $S$, and this does not relate to volcanic activities. Therefore, removing clouds is essential. To remove clouds, we use some Brightness Temperature Difference (BTD), which is sensitive to the cloud. Moreover, we verified the technique of cloud removal as compared with LiDAR data.

In this study, we apply the developed lava activity monitoring algorithm to the 2011 Shinmoedake eruptive activity with magma effusion, Japan. Moreover, the accuracy of the improved cloud discrimination algorithm and the effectiveness of lava activity monitoring by spatiotemporal changes of the singularity of brightness temperature are investigated.

\section{Shinmoedake Volcano}

Shinmoedake in the Kirishima volcano group is located at $31.931^{\circ} \mathrm{N}, 130.864^{\circ} \mathrm{E}$, the boundary of Kagoshima prefecture and Miyazaki prefecture in Kyushu, Japan (See Figure 1). It is an active andesitic stratovolcano. The history of Shinmoedake in 1700-2010 can be characterized in the following. It is a 
major activity in 1716-1717, with phreatic explosions and magma eruptions and phreatic explosions in $1822,1959,1991$ and 2008 [25-28].

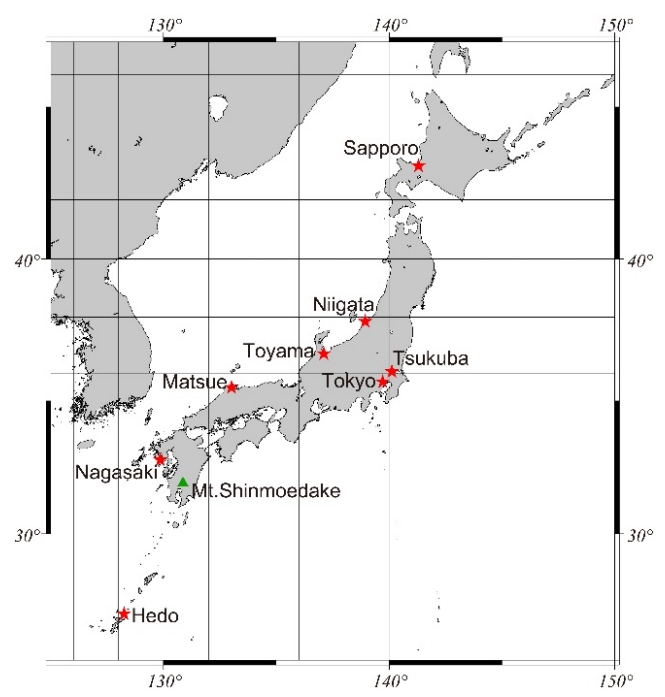

Figure 1. The location of the Shinmoedake and 8 LiDAR (light detection and ranging) sites.Green triangle and red star indicate the locations of Shinmoedake and a LiDAR site, respectively.

After these small phreatic events, the Shinmoedake volcano began a new phase of activity on 19 January 2011. The eruption commenced with a small phreatomagmatic event followed by subplinian events on 26 and 27 January 2011 [27-29]. Lava emerged as a dome in the summit crater on 27 January 2011, observed by SAR [30-32], and a small mound of lava was confirmed by aerial observation [33]. The mound is developed by a 500-m radius on 29 January. The lava filled the crater, and the development stopped at the beginning of February, and the maximum diameter is about $600 \mathrm{~m}$, and the volume is estimated by 10 million $\mathrm{m}^{3}$ [27-33]. During the subplinian events and lava dome growth, deflation of the deep magma chamber was observed by tiltmeters and GPS [27-29]. Some aerial pictures and figures during the 2011 activity are given in Appendix A [29]. Figures A1 and A2 indicate aerial photos of the summit crater and aerial thermal infrared images of the crater, respectively. Figure A3 show satellite SAR images.

The first explosive eruption occurred at 15:41 on 27 January. Explosive eruptions occurred 13 times by 1 March, most of them concentrated between 30 January and early February. The largest outbreak in 2011 was at 7:54 on 1 February. Eruptions have become intermittent since the beginning of February, and explosive eruptions occurred on 11, 14, 18 February and 1 March. Then, eruptive activity began to decrease in March. Their frequency and scale gradually declined. The number of eruptions after 2 March was five times in March, three times in April, one time in August and in September. No eruptive event occurred after the 2011 September 7 event [27-29]. In addition, swarming of low-frequency earthquakes was confirmed from 28 January to early February. There will be no doubt that magma will be supplied into the Shinmoedake Crater by early February.

\section{Data}

\subsection{MODIS}

The satellite Aqua was launched on 4 May 2002. NASA conducts the Earth Observation System (EOS) programs, and the Aqua project is one of them. The major mission of Aqua is to study the Earth's global dynamics - interrelation among the atmosphere, oceans and land surfaces. The Aqua satellite is operable at the altitude of $705 \mathrm{~km}$ with a sun-synchronous subrecurrent orbit and can monitor the same area on the same conditions. The recurrent period of the Aqua satellite is 16 days. This satellite has a descending orbit at midnight and an ascending orbit in the daytime. Since nighttime data are 
not affected by solar radiation, it is considered that we observe only the heat from the Earth's interior. The Aqua has six Earth-observing instruments on board, collecting a variety of global data sets. They are AIRS, AMSU, CERES, MODIS, AMSR-E and HSB. In this study, we use MODIS (MODerate-resolution Imaging Spectroradiometer). MODIS is the optical sensor with 36 observation wavelength bands. Sensors with the same specifications are installed on Terra and Aqua satellites. MODIS can observe a wide area $(2030 \times 1354 \mathrm{~km})$ at once. In this study, Band 20-which can measure surface and cloud temperature-and Bands 27, 31, 32, 34 and 35-which are used for removal of cloud effects-were analyzed. Table 1 describes MODIS channel characteristics and purpose in this study.

Table 1. MODIS (MODerate-resolution Imaging Spectroradiometer) band.

\begin{tabular}{|c|c|c|c|c|}
\hline \multirow{2}{*}{ Band } & \multirow{2}{*}{ Bandwidth $(\mu \mathrm{m})$} & Spectral Radiance & \multirow{2}{*}{$\begin{array}{l}\text { Spatial Resolution } \\
\text { (m) }\end{array}$} & \multirow{2}{*}{ Purpose in This Study } \\
\hline & & $\left(W / m^{2}-\mu m-s r\right)$ & & \\
\hline 1 & $0.620-0.670$ & 21.8 & \multirow{2}{*}{250} & \\
\hline 2 & $0.841-0.876$ & 24.7 & & \\
\hline 3 & $0.459-0.479$ & 35.3 & \multirow{5}{*}{500} & \\
\hline 4 & $0.545-0.565$ & 29.0 & & \\
\hline 5 & $1.230-1.250$ & 5.4 & & \\
\hline 6 & $1.628-1.652$ & 7.3 & & \\
\hline 7 & $2.105-2.155$ & 1.0 & & \\
\hline 8 & $0.405-0.420$ & 44.9 & \multirow{29}{*}{1000} & \multirow{19}{*}{$\begin{array}{l}\text { Hotspots detection and } \\
\text { Clouds discrimination }\end{array}$} \\
\hline 9 & $0.438-0.448$ & 41.9 & & \\
\hline 10 & $0.483-0.493$ & 32.1 & & \\
\hline 11 & $0.526-0.536$ & 27.9 & & \\
\hline 12 & $0.546-0.556$ & 21.0 & & \\
\hline 13 & $0.662-0.672$ & 9.5 & & \\
\hline 14 & $0.673-0.683$ & 8.7 & & \\
\hline 15 & $0.743-0.753$ & 10.2 & & \\
\hline 16 & $0.862-0.877$ & 6.2 & & \\
\hline 17 & $0.890-0.920$ & 10.0 & & \\
\hline 18 & $0.931-0.941$ & 3.6 & & \\
\hline 19 & $0.915-0.965$ & 15.0 & & \\
\hline $20 *$ & $3.660-3.840$ & $0.45(300 \mathrm{~K})$ & & \\
\hline 21 & $3.929-3.989$ & $2.38(335 \mathrm{~K})$ & & \\
\hline 22 & $3.929-3.989$ & $0.67(300 \mathrm{~K})$ & & \\
\hline 23 & $4.020-4.080$ & $0.79(300 \mathrm{~K})$ & & \\
\hline 24 & $4.433-4.498$ & $0.17(250 \mathrm{~K})$ & & \\
\hline 25 & $4.482-4.549$ & $0.59(275 \mathrm{~K})$ & & \\
\hline 26 & $1.360-1.390$ & 6.00 & & \\
\hline $27 *$ & $6.535-6.895$ & $1.16(240 \mathrm{~K})$ & & \multirow[t]{4}{*}{ Clouds discrimination } \\
\hline 28 & $7.175-7.475$ & $2.18(250 \mathrm{~K})$ & & \\
\hline 29 & $8.400-8.700$ & $9.58(300 \mathrm{~K})$ & & \\
\hline 30 & $9.580-9.880$ & $3.69(250 \mathrm{~K})$ & & \\
\hline $31 *$ & $10.780-11.280$ & $9.55(300 \mathrm{~K})$ & & Clouds discrimination \\
\hline $32 *$ & $11.770-12.270$ & $8.94(300 \mathrm{~K})$ & & Clouds discrimination \\
\hline 33 & $13.185-13.485$ & $4.52(260 \mathrm{~K})$ & & \\
\hline $34 *$ & $13.485-13.785$ & $3.76(250 \mathrm{~K})$ & & Clouds discrimination \\
\hline $35 *$ & $13.785-14.085$ & $3.11(240 \mathrm{~K})$ & & Clouds discrimination \\
\hline 36 & $14.085-14.385$ & $2.08(220 \mathrm{~K})$ & & \\
\hline
\end{tabular}

\section{2. $L i D A R$}

LiDAR (Light Detection And Ranging) is equipment observing the distribution of a particulate matter floating in the sky by firing a laser beam and measuring light to be scattered with particulate 
matters. LiDAR uses electromagnetic waves with wavelengths much shorter than RADAR. Therefore, LiDAR is suitable for detecting aerosols and cloud particles than RADAR, and it is useful for atmospheric research and meteorology [34,35]. In this paper, we compare the cloud discrimination results of MODIS data with the ground LiDAR data. In other words, we evaluated the cloud discrimination result by MODIS using LiDAR data. Here, the ground LiDAR continuous observation data operated by the National Institute for Environmental Studies (NIES), Tsukuba, Japan)) was used [34]. LiDAR observations are performed every $15 \mathrm{~min}$, and the attenuated backscattering coefficient is obtained up to $18,000 \mathrm{~m}$ above the ground at a resolution of $30 \mathrm{~m}$. We use the data of $532 \mathrm{~nm}$.

\section{Data Processing}

\subsection{Bright Temperature Analysis of MODIS Data}

Nighttime MODIS binary data (AM 0:30-2:30 in local time) are converted into brightness temperature and result in the daily map of the brightness temperature, which has an area of $1^{\circ} \times 1^{\circ}$ study area centered at target pixel of the summit or the crater. The analyzed period is from 1 January 2003, to 31 December 2011, for Shinmoedake.

The temporal variation of brightness temperature for all pixels is investigated. Brightness temperature changes according to the emission are derived from the physical temperature of the surface and various factors such as climate conditions. The attempt to compare the spatial variation of brightness temperatures at one point to that of the reference points is considered. It is found that as the distance between these two points decreases, there is a tendency that their correlation is high. Conversely, when the distance increases, gradually, the correlation decreases. It means the factor to affect brightness temperature has its own scale. Therefore, if an appropriate reference distance is determined, a specific factor can be removed from the original fluctuation.

The spatial difference of brightness temperature is defined by the brightness temperature at the focused point (FP) and the four reference points (RP) with a certain distance to the north, east, south and west directions from the FP $[9,36]$.

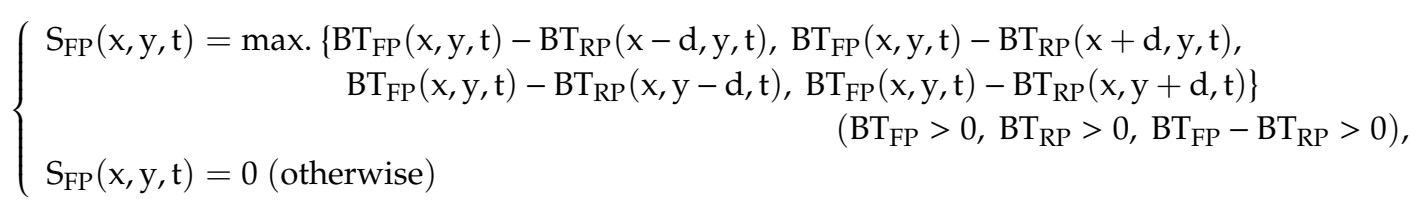

Here, $\mathrm{S}_{\mathrm{FP}}, \mathrm{BT}_{\mathrm{FP}}$ and $\mathrm{BT}_{\mathrm{RP}}$ are spatial differences of brightness temperatures, brightness temperatures at the focused point and the reference point, respectively. $\mathrm{S}_{\mathrm{FP}}$ is computed for all pixels in one scene. Then, the time variation of $S_{\mathrm{FP}}$ is investigated for all pixels from the start of the analysis; and the time for which $\mathrm{S}_{\mathrm{FP}}$ becomes a maximum value in the series is registered for each $\mathrm{FP}$. The procedure is illustrated in Figure 2.

We calculate the range correlation from the summit of each volcano as follows;

$$
\rho=\frac{\frac{1}{n} \sum_{i=1}^{n}\left(B T_{F P}-\mu_{F P}\right)\left(B T_{R P}-\mu_{R P}\right)}{\sigma_{F P} \sigma_{R P}},
$$

where $\rho$ is the correlation factor, $\mu_{F P}$ and $\mu_{R P}$ are average of $\mathrm{BT}_{\mathrm{FP}}$ and $\mathrm{BT}_{\mathrm{RP}}, \sigma_{F P}$ and $\sigma_{R P}$ indicates standard deviations of $\mathrm{BT}_{\mathrm{FP}}$ and $\mathrm{BT}_{\mathrm{RP}}$, respectively. Figure 3 shows the variation of the correlation factor for Shinmoedake for each year. Because eruption occurred in 2011, the correlation of 2011 is much lower than for other years. We adjust the threshold of high correlation level $(=0.95)$ to detect minute thermal anomalies, and the distance between FP and RP is $0.05^{\circ}(5 \mathrm{~km})$ in this study. 


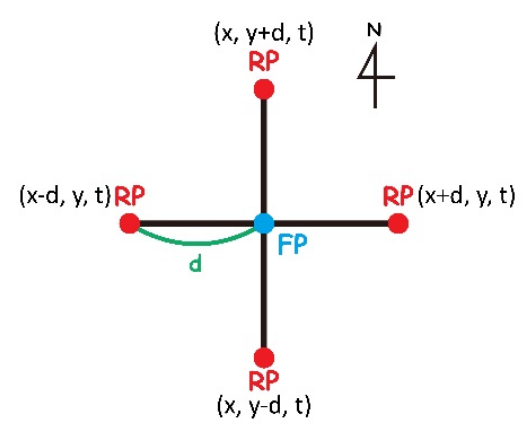

(a)

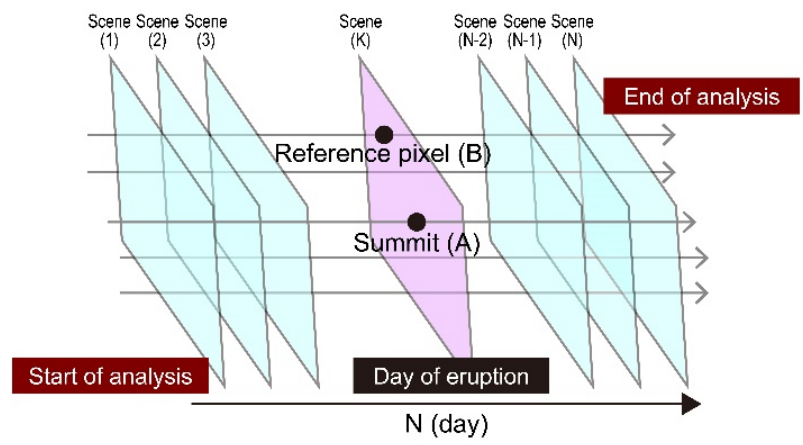

(b)

Figure 2. Schematic illustrations of the computation procedure in this study. (a) Relationship between a focal point and corresponding four reference points; (b) time-series analysis of scenes.
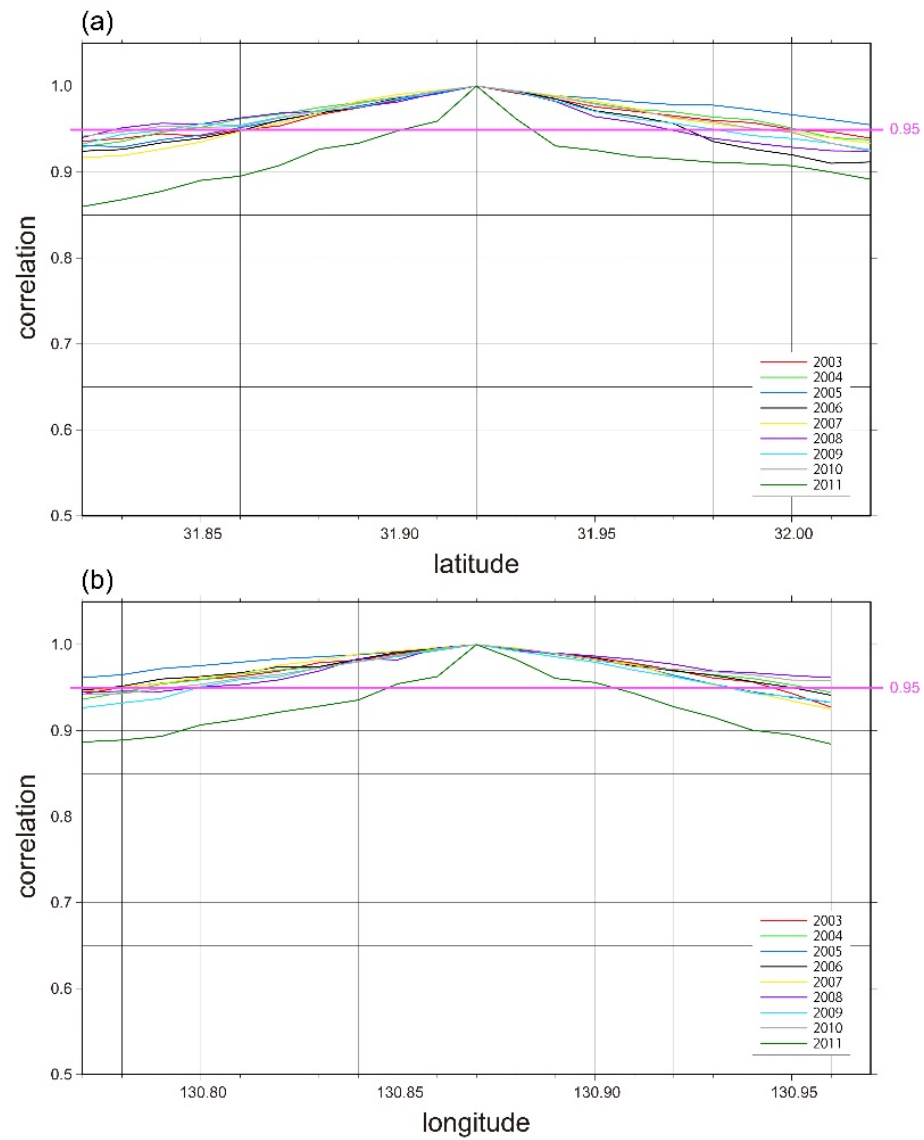

Figure 3. Range correlations from the summit crater of Shinmoedake along (a) latitude and (b) longitude each year. Colors indicate the year. Green line corresponds to the year of 2011 when is the volcanically active year.

\subsection{Cloud Effect Reduction}

If we subtract brightness temperatures at the RP with that of clouds from the $\mathrm{FP}$, an inaccurate $\mathrm{S}_{\mathrm{FP}}$ value is obtained, because the brightness temperature of the cloud pixel is lower than that of the surface pixels. Therefore, the removal of cloud effects is crucial. To remove cloud effects with MODIS data, Noguchi et al. use radiances collected at bands 31 and 32. Noguchi et al. adopt a similar approach (i.e., RST-based) applied by Pergola et al. on AVHRR data (i.e., bands 4 and 5, at $\sim 11 \mu \mathrm{m}$ and $\sim 12 \mu \mathrm{m}$, respectively) to recognize meteorological clouds [3,9]. Noguchi et al. follows their approach and apply to detect thermal changes possibly associated with volcanic activity in Mt. Merapi. Indonesia 
and Mt. Asama, Japan [9]. Regarding the case of Mt. Merapi, the results show the effectiveness of the cloud detection, but in the case of Mt. Asama, the removal of clouds effects is found insufficient. In this study, a different approach to remove cloud effects is adopted In the Noguchi method, if BTD is lower than the monthly average of BTD-1 $\sigma$, then that pixel is classified as a cloud pixel [9]. Here, $\sigma$ is a standard deviation over one month. This method can remove clouds in tropical areas such as Indonesia. However, it cannot remove cloud in temperate zones such as Japan. This is because, in tropical regions, almost all clouds are cumulonimbus. However, in temperate zones, there are many kinds of clouds. Therefore, in this study, we use not only BTD between bands 31 and 32, but also other BTDs (bands 20-31, bands 34-35, bands 31-27, where the wavelength of band 20, 27, 34 and 35 are 3.7 , $3.9,13.7$ and $13.9 \mu \mathrm{m}$, respectively.

Regarding cloud detection, five tests are examined for all satellite data. If a pixel passes the Test 1, it can proceed to Test 2; if the pixel passes the Test 2, then it can proceed to Test 3, etc. Finally, only the pixel that passed all five tests can be regarded as a clear pixel that is not a cloud pixel and is used to further analysis. Figure 4 illustrates the general concept of the proposed cloud discrimination procedure and detailed procedures in the tests.

At first, we select the pixel whose brightness temperature of band 20 is higher than $260 \mathrm{~K}$. Then, we calculate the temporal average $\mu$ and standard deviation $\sigma$ of the BTDs for each month. All pixels whose distance from the mean value is larger than a prescribed value $(\mu+k \sigma)$ are rejected. As Test 2 , BTD of band 34-band 35 is investigated. If the BTD is small, the pixel is likely a cloud. The BTD histogram is considered to be a mixture of many normal distributions.

Specifically, since the purpose of this study is to distinguish between the cloud region and the clear region, the pixels in which the brightness temperature of band 20 is less than $260 \mathrm{~K}$ are rejected as clouds in Test 1 . A histogram is created using the pixels, the average value $\mu$ and standard deviation $\sigma$ of the BTD is computed, and pixels that do not satisfy the following formula are rejected,

$$
\operatorname{BTD}_{34-35}(\mathrm{t})-\mu<\mathrm{k \sigma}
$$

where $\mathrm{k}$ is the coefficient, which is determined by comparison with LiDAR data and described later. A new average value $\mu^{\prime}$ and standard deviation $\sigma^{\prime}$ are calculated from the remaining data, and pixels that do not satisfy the formula are rejected. This procedure is repeated until there are no more pixels to be rejected, and the final remaining pixels are set as candidates for the clear sky area, and the next test is performed. Figure 5 shows the results of cloud discrimination with Tests 1 and 2, as described in Figure $4 \mathrm{~b}$. Pixels in the red colored area in Figure 5c correspond to the clear region.

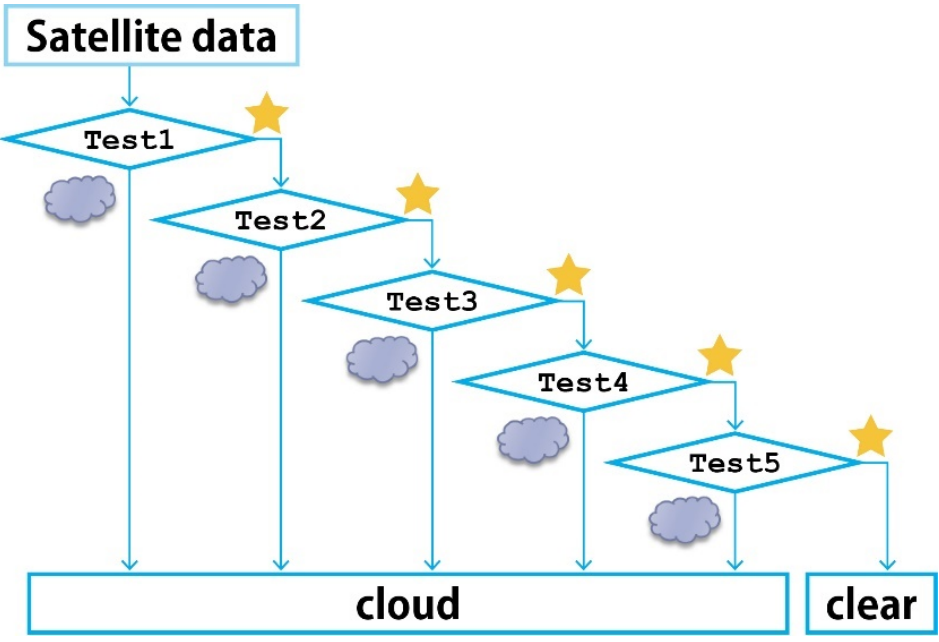

(a)

Figure 4. Cont. 


\section{Method: Cloud pixel rejection}

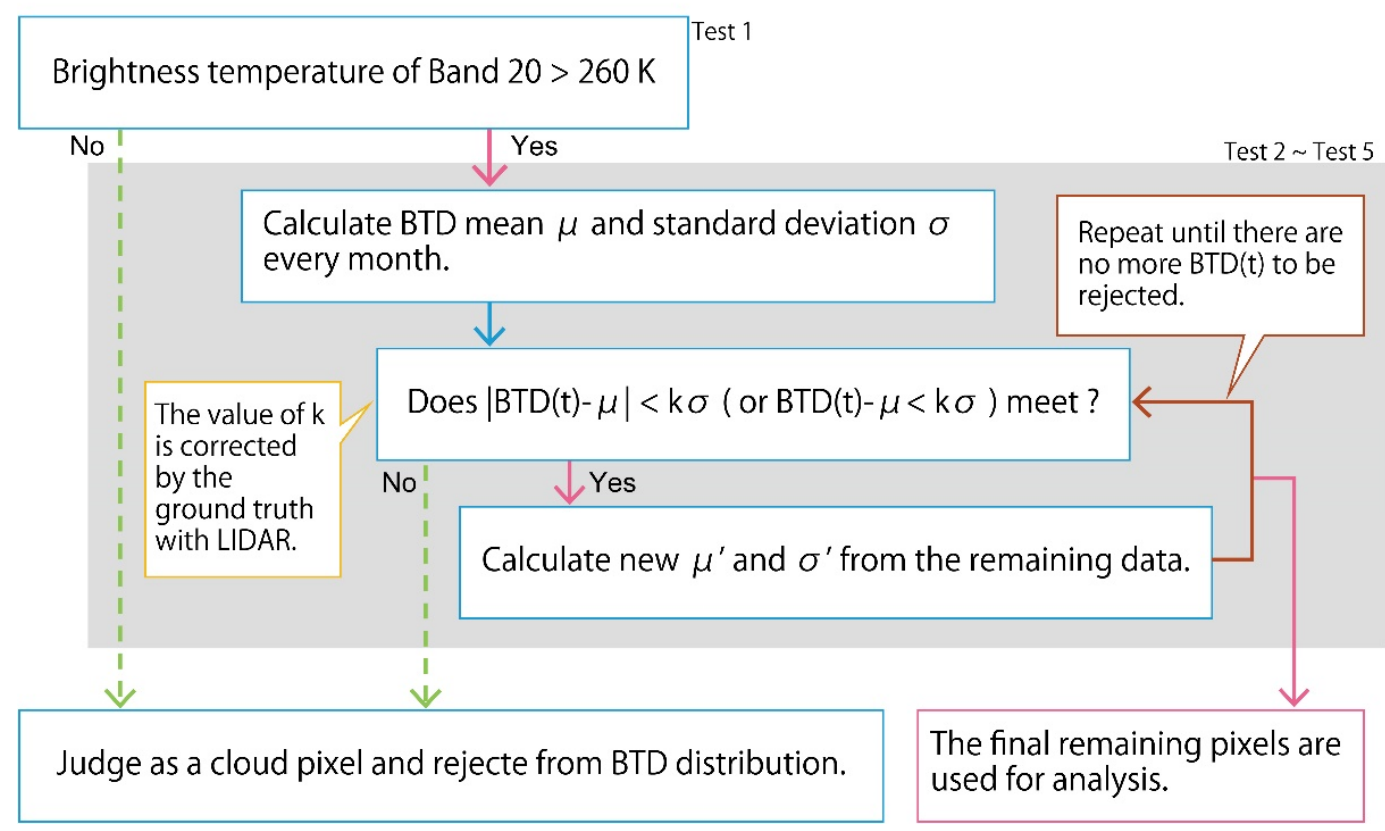

(b)

Figure 4. Schematic view of the cloud discrimination method. (a) General concept of cloud discrimination. Each test corresponds to the cloud reduction on a different level. (b) detailed explanation of the cloud discrimination for Tests $2-5$.

A similar cloud discrimination procedure is performed on the $\mathrm{BTD}_{31-27}$ between bands 31 and 27, as Test 3.

$$
\mathrm{BTD}_{31-27}(\mathrm{t})-\mu<\mathrm{k \sigma}
$$

Regarding the $\mathrm{BTD}_{31-32}$ of bands 31 and 32 , Test 4 , the difference in this value corresponds to the amount of water vapor in the atmosphere, which is negative for lower clouds and smaller for thick upper clouds (cumulonimbus). This value becomes large when there is a thin upper cloud. Then, the criterion of the cloud is as follows;

$$
\left|\mathrm{BTD}_{31-32}(\mathrm{t})-\mu\right|<\mathrm{k} \sigma,
$$

where $\mathrm{k}$ is a coefficient, which is determined by comparison with LiDAR data.

As for Test 5 of BTD $20-31$ between band 20 and band 31, lower clouds show negative values and upper clouds indicate higher values. Therefore, the definition of cloud pixel is

$$
\left|\mathrm{BTD}_{20-31}(\mathrm{t})-\mu\right|<\mathrm{k} \sigma,
$$

where $\mathrm{k}$ is a coefficient, which is determined by comparison with LiDAR data. In this test, we must pay attention to the result of Test 4 because $\mathrm{BTD}_{31-32}(\mathrm{t})$ shows high values in the case of volcanic activity. Based on the evaluation by LiDAR in the following subsection, $\mathrm{k}$ values are experimentally given by $1.8,2.2,2.0$ and 1.2 for Tests $2-5$, respectively. 


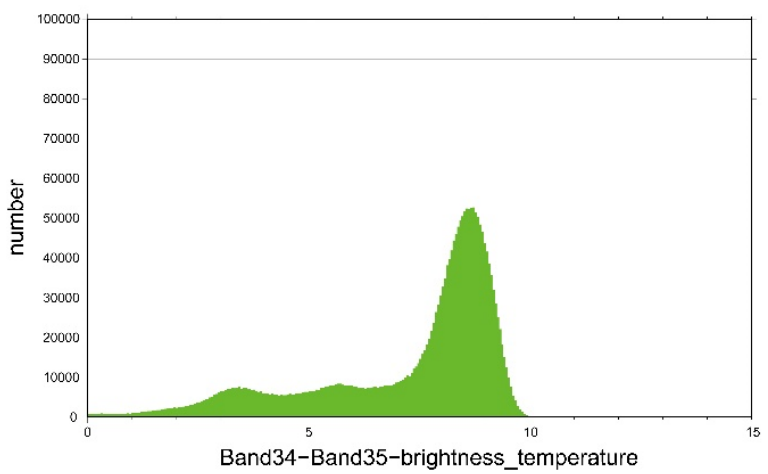

(a)

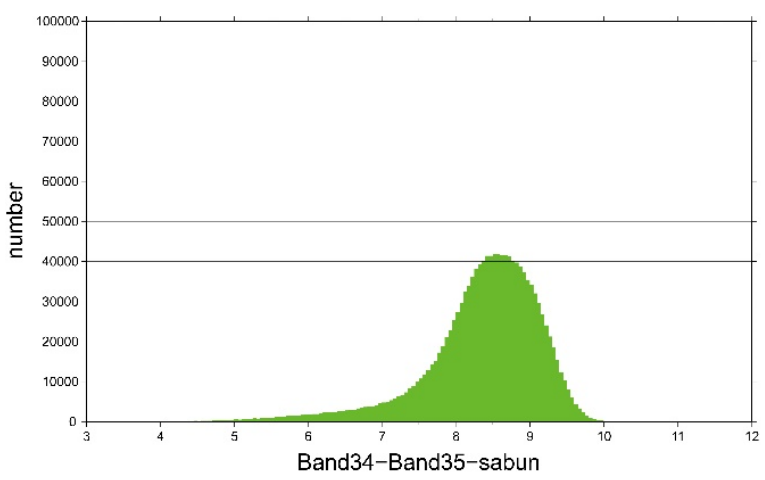

(b)

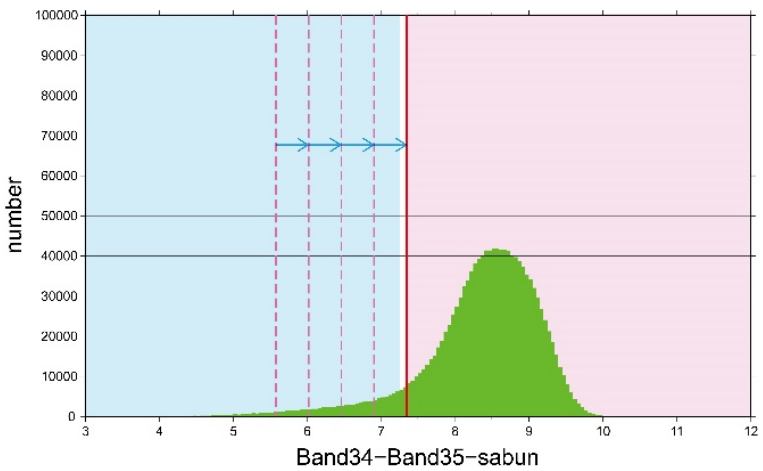

(c)

Figure 5. Distributions of the brightness temperature difference (BTD) between band 34 and band 35 in October at Shinmoedake. (a) Original distribution of $\mathrm{BTD}_{34-35}$. The distribution seems to be composed

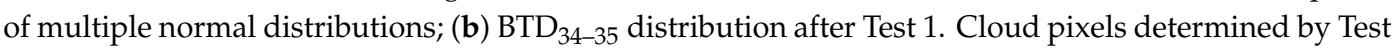
1 are removed; (c) schematic image of the repeat of the cloud reduction process. A new average value $\mu^{\prime}$ and standard deviation $\sigma^{\prime}$ are calculated from the remaining data, and pixels that do not satisfy the formula are rejected. Finally, pixels in the red area are fixed as clear and the blue region rejected as clouds.

\subsection{Evaluation of Cloud Discrimination by Ground LiDAR}

In this study, MODIS nighttime values are used. Therefore, the evaluation of cloud discrimination described above cannot be performed using a satellite visible image. Therefore, we decide to verify using ground LiDAR data. In this study, we use LiDAR continuous observation data operated by NIES, Japan. The data are obtained through the website of AD-Net, Asian dust and aerosol lidar observation network, NIES, Japan [37]. Details of the LiDAR network are given in [34,35]. Data from 1 January 2005 to 31 December 2008 are used. Since there was no LiDAR data available near the Shinmoedake 
volcano, we compare the LiDAR data and MODIS data over eight sites that are not directly related to the volcano: Sapporo, Niigata, Tsukuba, Tokyo, Toyama, Nagasaki, Matsue and Hedo, Japan. The map and the detailed locations are provided in Figure 1 and Table 2, respectively [34,37]. In this paper, the results at Tsukuba station in December are shown as examples.

Table 2. Coordinates of Shinmoe-dake and LiDAR sites.

\begin{tabular}{cccccccccc}
\hline & Shinmoe & Sapporo & Niigata & Toyama & Tsukuba & Tokyo & Matsue & Nagasaki & Hedo \\
\hline Latitude & $31.931^{\circ}$ & $43.10^{\circ}$ & $37.84^{\circ}$ & $36.70^{\circ}$ & $36.05^{\circ}$ & $35.69^{\circ}$ & $35.48^{\circ}$ & $33.81^{\circ}$ & $26.87^{\circ}$ \\
Longitude & $130.864^{\circ}$ & $141.30^{\circ}$ & $138.94^{\circ}$ & $137.10^{\circ}$ & $140.12^{\circ}$ & $139.71^{\circ}$ & $133.01^{\circ}$ & $129.85^{\circ}$ & $128.25^{\circ}$ \\
\hline
\end{tabular}

Figure 6 shows the results of the comparison between cloud discrimination results of MODIS and LiDAR data at the LiDAR site. These figures are scatter plots in which the ordinate and abscissa represent the BTD values used for cloud discrimination, Tests $2-5$. In figures, the red circle corresponds to the BTD value of the day when it is determined that there is no cloud by LiDAR, and the black-cross indicates the BTD value of the day when it is determined that there is a cloud by LiDAR. The area surrounded by the blue lines represents the area determined to be cloudless by the cloud discrimination based on the BTD method of MODIS data proposed in this paper. The blue lines in Figure 6a,b are criteria for eliminating cloud pixels in this study. The green line in Figure $6 \mathrm{a}$ is the threshold between cloud and clear in a previous study [9]. The pixel with BTD between band 31 and band 32 is lower than the green line (green area) is identified and dismissed as a cloud pixel in the previous study [9]. From Figure 6, it can be seen that the proposed BTD method succeeds in clustering the cloud and non-cloud regions. It is also well understood that the previous cloud discrimination method using only bands 31 and 32 is not sufficient in Japan. It is safe to say that the proposed method is one of the possible ways to discriminate cloud pixels in nighttime data in the temperate zone area more accurately. We got similar results regarding the other LiDAR sites.

Actually, in order to set the threshold value that can more accurately distinguish the cloud area from the clear zone, the values of the parameter $k$ in Equations (3)-(6) (Tests 2-5) are adjusted while comparing with the scatter charts as shown in Figure 6. In this procedure, a different value of $k$ is set at each LiDAR site, practically. In this paper, the average value of 8 sites is adopted as the value of $k$ to be used at Shinmoedake. It can be said to be the representative over the Japan region.

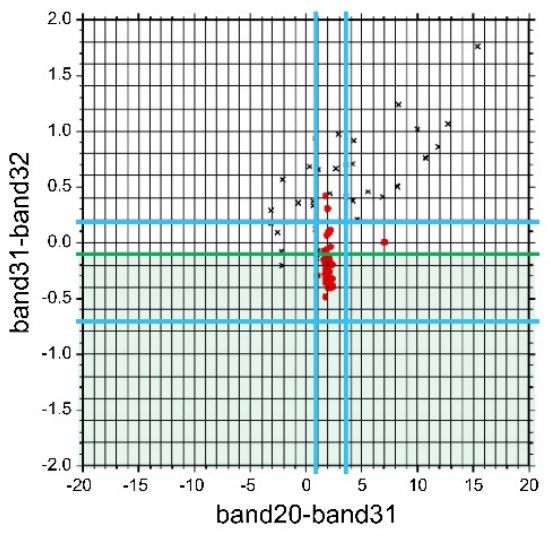

(a)

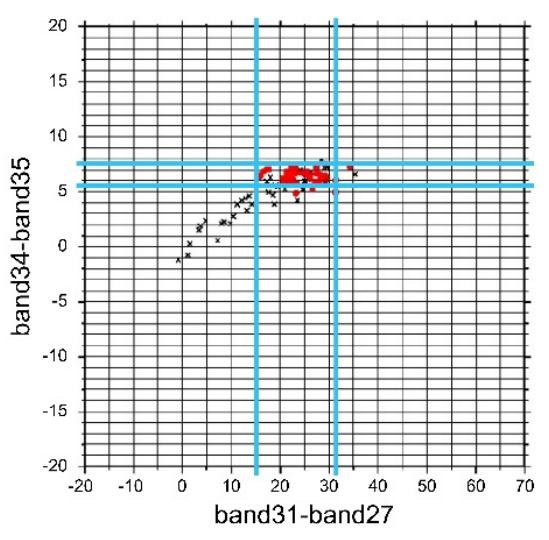

(b)

Figure 6. Scatter diagrams of BTDs for cloud discrimination at Tsukuba, Japan. (a) BTD $31-32$ vs. $\mathrm{BTD}_{20-31}$; (b) BTD $\mathrm{BT}_{34-35}$ vs. BTD $31-27$. Blue lines in panels (a) and (b) correspond to the upper or lower threshold values in BTDs between clear and cloud pixels for the proposed method in this study. Green line in panel (a) indicates the threshold of the previous Noguchi method. Below this line, it is determined by clear pixels. Red and black symbols correspond to clear and cloud pixels distinguished by LiDAR data. 


\subsection{Spatiotemporal Singularity}

In order to obtain the temporal singularity of the evaluation function $S$ obtained in equation (1), the singularity, deviation rate, $\delta$ is defined as follows,

$$
\delta=S_{F P} / \overline{S_{F P}},
$$

where $\overline{S_{F P}}$ is the average of $S_{F P}$ over the analyzed period (9 years). In this study, we investigate the relationship between the spatiotemporal variation of $\delta$ and the volcanic activity accompanied by lava activity.

In comparison with other systems that also exploit MODIS data, it should be noted that the applied method is a single channel approach. In fact, the detection of the volcanic hotspots is only based on radiances acquired in the MIR spectral range (i.e., band 20 of MODIS sensor). Instead, the other systems, e.g., RST VOLC, MODVOLC, MIROVA, HOTVOLC, HOTSAT and AVHotRR, use also radiances acquired in the TIR wavelength (i.e., band 31 and/or band 32), and they can be classified as dual channel approaches. In particular, some of these systems use the MIR and TIR radiances to compute differential indices (i.e., HOTSAT) and normalized differential indices (i.e., MODVOLC, MIROVA, HOTVOLC) on analyzed scene. Hence, volcanic hotspots are detected by means of fixed threshold tests and/or contextual approaches. Regarding the AVHotRR method, it uses data recorded in the MIR and TIR bands to resolve numeric simulations (e.g., dual-band techniques) for hotspot

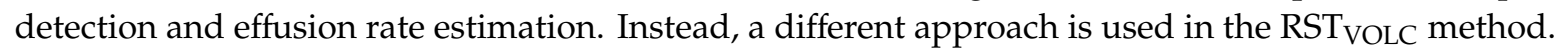
In this method, multiyear homogenous time-series of satellite records are exploited to characterize (in terms of expected value and its historical variability) each location of the analyzed portion of the satellite scene. Volcanic anomalies are identified by means of a local variation index. In [38], it is possible to find a detailed description of the systems as mentioned above and the other methods devoted to the detection of volcanic anomalies, as well as their historical review.

The Noguchi singularity method can be considered as a hybrid method. Volcanic anomalies are identified on the base of a multitemporal analysis of a spatial differential variable (i.e., $S_{F P}$ ), which was computed as in a contextual approach (see Section 4.1).

It worth noting that by using a statistical approach of homogenous long time-series (as in RST $_{\text {VOLC }}$ ), it is expected a reduction of the false alarms (e.g., possible anomalies due to site effects). Nevertheless, the results of the analysis could be influenced by the not correct discrimination of clouds (over the summit and/or the reference pixels), that lead to a wrong estimation of the $\mathrm{S}_{\mathrm{FP}}$.

Finally, even if the false negatives can be observed due to the use of the radiances not atmospherically correct, here the TOA radiances are taken in account to avoid that, the use of the not appropriate atmospheric models (i.e., standard models) could generate a wrong estimation of the reflectance and consequent proliferation of anomalies independent from volcanic activity.

\section{Results}

Figure 7 shows an example of the two-dimensional brightness temperature map of band 20 in the $\pm 0.5^{\circ}$ area centering on the summit crater of Shinmoedake, which was observed at UT (Universal Time) 17:10 on 29 January (LT (Local Time) 02:10 on 30 January), 2011. The brightness temperature is indicated by the color bar in figure. According to the report, lava effusion was confirmed in the crater lake on 27 January by SAR observation, and it had grown to a diameter of $500 \mathrm{~m}$ on 29 January [27-33]. Moreover, hot volcanic products such as cinders were deposited in the southeast area from the crater. The hotspots in figure can be related to the volcanic activity of Shinmoedake. Therefore, we investigate the temporal changes of brightness temperature and singularity at each pixel. 


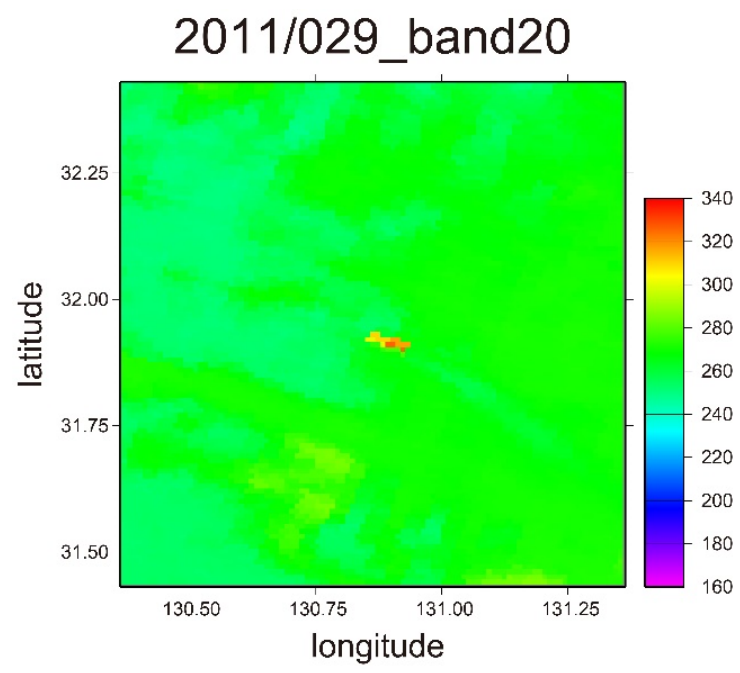

Figure 7. Example of a 2D distribution map of the brightness temperature of band 20. Brightness temperature is given by legend. A and B in Figure $2 \mathrm{~b}$ corresponds to the locations near the summit crater and the region far from the summit, respectively. For Japan, LT $=\mathrm{UT}+9 \mathrm{~h}$. The nighttime images of Aqua have one day difference in date between LT and UT.

Figure 8 shows the temporal variations of brightness temperature and the singularity of $S, \delta$, which provides a spatial difference of brightness temperature, at the summit of Shinmoedake, for all analyzed periods. In figure, the top panel (a) indicates the variation of brightness temperature of band 20 , and the lower two panels $(b, c)$ show the variation of $\delta$. The panels $(b, c)$ correspond to the result for the previous Noguchi method [9] and the proposed method for cloud discrimination, respectively. In panels $(b, c)$, anomalous $\delta$ is defined by the mean value of $\delta+6 \sigma$, which is given by a green line, and red vertical lines indicate the days when $\delta$ value exceeds the threshold. These anomalous days are concentrated in the volcanically highly active period, colored by pink in the panel (c). However, some anomalies are detected in volcanically inactive periods in the panel (b). These are errors caused by cloud pixels. It is highly suggestive that the new method can reduce faint changes due to clouds. From the distribution of singularity values over the analyzed period, the values in the case of the lava ejected to the surface are considerably large. These are confirmed through Figure 8c and Figure 10a. The $6 \sigma$ threshold was also effective for monitoring volcanic activity with lava activity in Indonesia by the Noguchi method, which is the prototype in this study. In addition, even though there were spurious when the Noguchi method was applied to monitor Mt. Asama in Japan, the 6 $\sigma$ threshold seems to be useful because the activity with lava could successfully be detected [9]. Taking account of these empirical facts, we have chosen the $6 \sigma$ threshold in this study. 


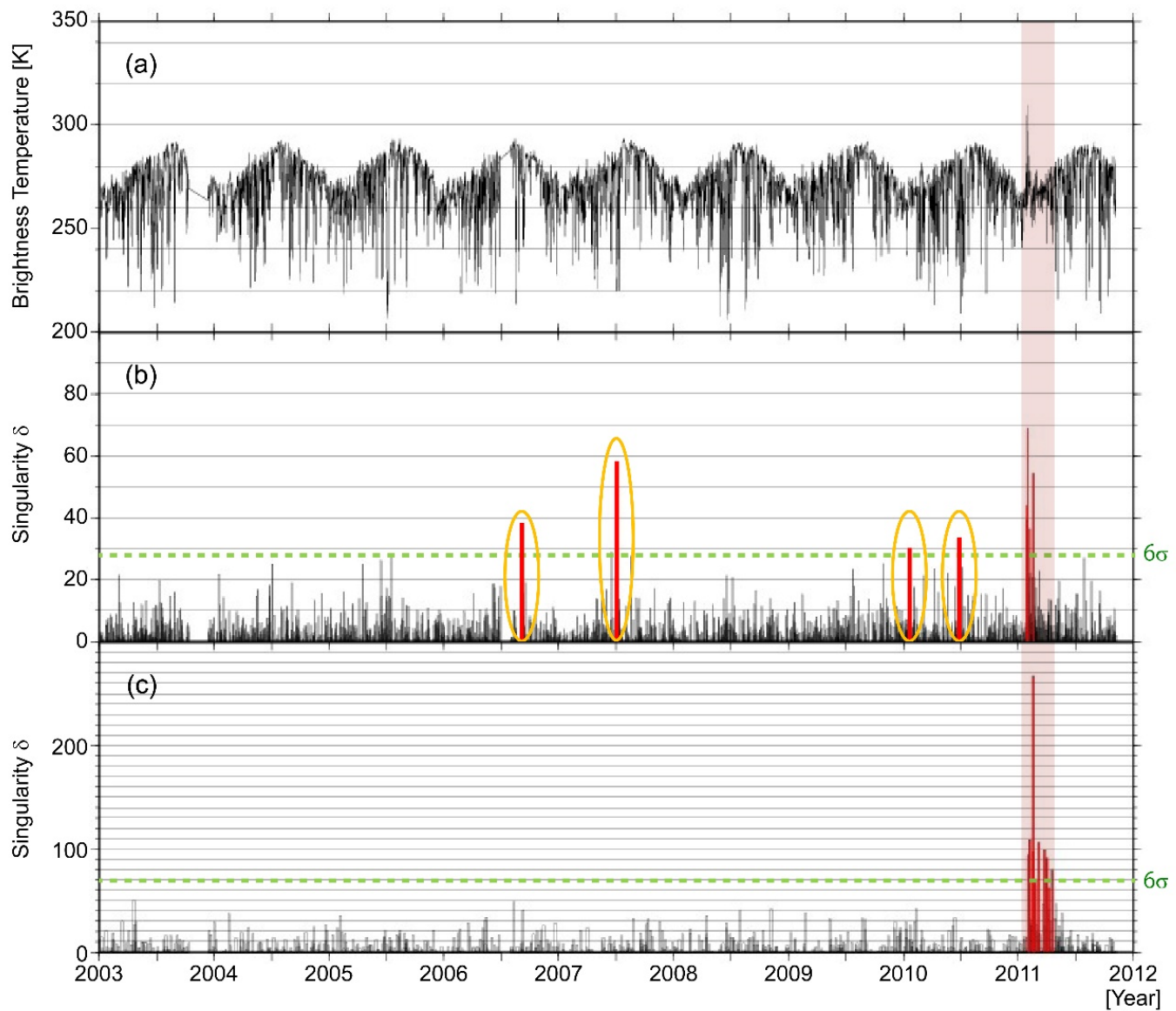

Figure 8. Temporal variation of brightness temperature and singularity at the summit crater of Shinmoedake from 1 January 2003 to 31 December 2011 in UT. (a) Brightness temperature of band 20 (raw data); (b) singularity with the Noguchi method for cloud discrimination; (c) singularity with this study for cloud detection. Green lines in $(\mathbf{b}, \mathbf{c})$ represent the threshold for the anomaly in singularity defined by average $+6 \sigma$. Red vertical bars show the day when the singularity exceeds the threshold. The period with pink color is the period of a volcanically active period. Yellow ellipses are false changes due to errors in cloud detection.

\section{Discussions}

In Figure $8 c$, the first specific anomaly was detected on 26 January. The maximum value is detected on 30 January. The second peak value is observed on 2 February. The remarkable singularity in $\mathrm{d}$ is continuously detected and terminates in March. This is the only period in which abnormal values appear at the summit (crater) over the analyzed nine years. The eruptive activity of Shinmoedake in 2011 began on 19 January and ended on 7 September. Considering from the records of GPS crustal deformation and earthquakes comprehensively, the 2011 activity of Shinmoedake shows that from around December 2009, magma supplied to a magma chamber about 6-10 km depth at several $\mathrm{km}$ northwest of Shinmoedake summit, and it is suggested that it erupted at Shinmoedake in 2011 [27-29,31-33,39-41].

As for the lava effusion, the expansion beneath the summit of Shinmoedake was confirmed on 18 January 2011 from tiltmeter data [27-29,31,32]. There was a small phreatomagmatic eruption at 1:27 on 19 January and a subplinian eruption on 26 January after a small eruption. The plume reached 3000-7000 $\mathrm{m}$ and at about 16:00 (LT), tiltmeter monitoring the magma chamber in the northwest of Shinmoedake recorded a fluctuation indicating underground contraction. A precursory fluctuation of tiltmeter showing expansion just under Shinmoedake was also recorded several hours before the subplinian eruption. In addition, satellite SAR image analysis confirmed the eruption of lava in the 
crater on 27 January (See Figure A3 in Appendix A). On 28 January, Earthquake Research Institute, the University of Tokyo confirmed the appearance of lava with a diameter of several tens of meters in the crater. It is reported that the erupted lava expanded to a diameter of $500 \mathrm{~m}$ on 29 January and reached a diameter of $600 \mathrm{~m}$ in early February by aerial photos (See Figure A1 in Appendix A). After that, there were no significant changes in the size and shape of the lava in the crater and the condition of ejecting fumarole gases around it [27-29,31-33,39-41].

Moreover, preliminary results of the implementation of an RST-based [42,43] approach on ASTER TIR data also provide a certain certificate of the presence of lava in the summit crater of Shinmoedake. Figure 9 shows anomalous values (i.e., pixels exceed three times higher than their historical variability) identified by ASTER scenes on 31 January and 7 February 2011.

(a) 31 January 2011

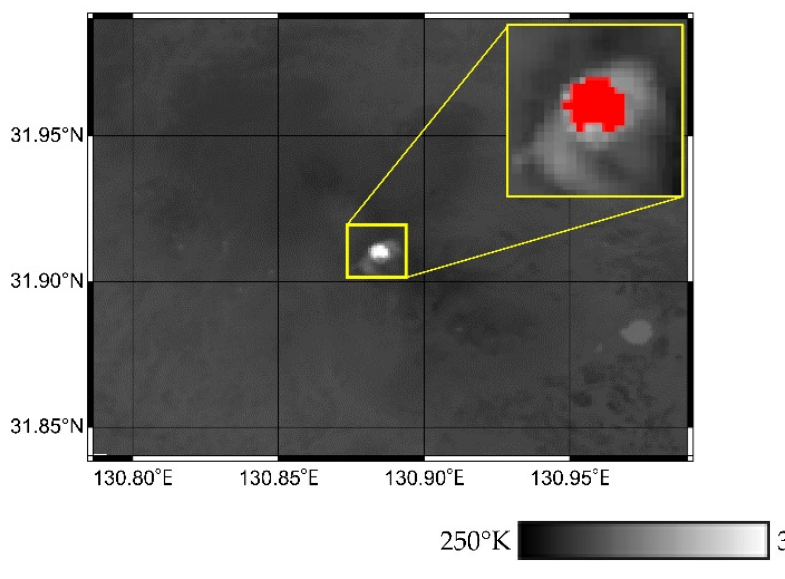

(b) 7 February 2011

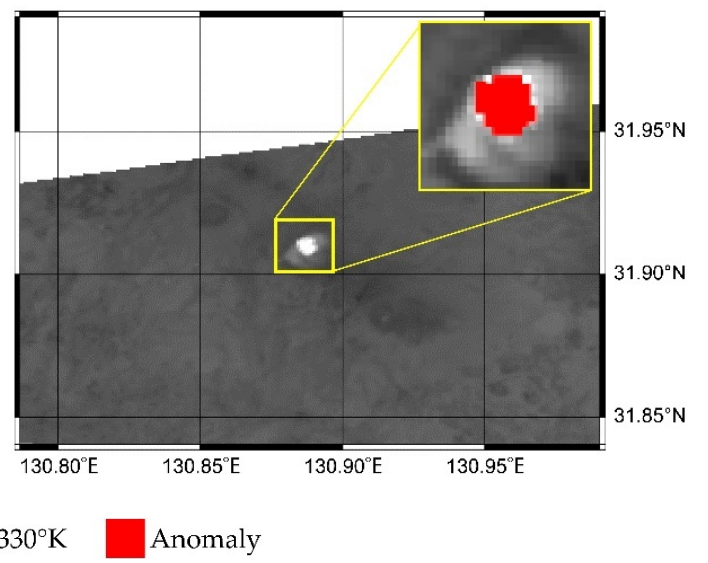

Figure 9. Advanced Spaceborne Thermal Emission and Reflection Radiometer (ASTER) Thermal InfraRed (TIR) data (band 13: 10.25-10.95 $\mu \mathrm{m}$ ). (a) 13:23:52 on 31 January 2011 (UT) (b) 13:29:57 on 7 February 2011 (UT). Red pixels on the zoomed portion indicate anomalous pixels identified by an RST-based analysis on 20 years (2000-2020) of ASTER TIR data.

According to the ground surface temperature distribution by aerial thermal infrared images (See Figure A2 in Appendix A), the central part of the lava dome was very hot at the beginning of the magma eruption in January and early February [27-33,39-41]. However, when the supply from the underground stopped, the surface temperature of the lava gradually decreased. From March, the fumarole gases emitted from the center of the crater was only from the edge of the lava that filled the crater, and the relatively high temperature area was recorded only around the fumarole. Almost no hot part was detected in the crater in May, and surface temperature in the crater was below $50{ }^{\circ} \mathrm{C}$ in September [28,29].

Changes in lava size and temperature changes in the crater from aerial and satellite SAR observations strongly validate that our results are effective [27-33]. In particular, aerial thermal infrared images and the formation of lava domes inside the crater are intermittent, but they suggest that the maximum heat release could be expected from the end of January to the beginning of February.

Earthquake, tilt and tephra data also indicate that magma supply into the crater from the underground is from around 28 January and terminated in early February [27-29,39-41]. Therefore, it is expected that the surface temperature of lava in the crater will gradually decrease thereafter and become undetectable in May.

Marchese et al. reported the eruptive activity of Shinmoedake on 26-27 January 2011 using sunflower MTSAT-2 [44]. They report an increase in sensitivity at 3.5-4.0 $\mu \mathrm{m}$ on days 26 and 27 using the RST $_{\text {VOLC }}$ algorithm $[3,8,10]$. The singularity in Figure 8 also took an abnormally large value for the first time on 26 January. Therefore, we compare the results of applying the RST $_{\text {VOLC }}$ algorithm and the singularity algorithm proposed in this study to the MODIS data for the 2011 Shinmoedake volcanic 
activity. Here, since it is difficult to evaluate with only the summit pixel, it is difficult to evaluate, we use nine pixels near the summit (a total of nine pixels: the summit pixel + eight surrounding pixels). The results are shown in Figure 10.

Figure 10a shows the temporal change of singularity proposed in this study (blue dot). Anomalous value in singularity near the summit is defined by greater than about 80 (See Figure $8 \mathrm{c}$ ). Figure 10b indicates the variations of RST VOLC calculated in the mid-infrared and thermal infrared bands (red dot) and that computed in the mid-infrared bands (black dot). The green symbol on the axis is the day when the area near the summit was covered with clouds and RST VOLC could not be calculated. When the pixel has RST VOLC values of greater than 3, that is both red and black dots exceed 3, the pixel is determined as the volcanic hotspot. You can see that the trends among these figures are mostly the same. That is, the first abnormal increase was recognized on 26 January, and the maximum increase was 30 January. Moreover, also, large values were found to be concentrated from 26 January to early February and the middle of February in UT.

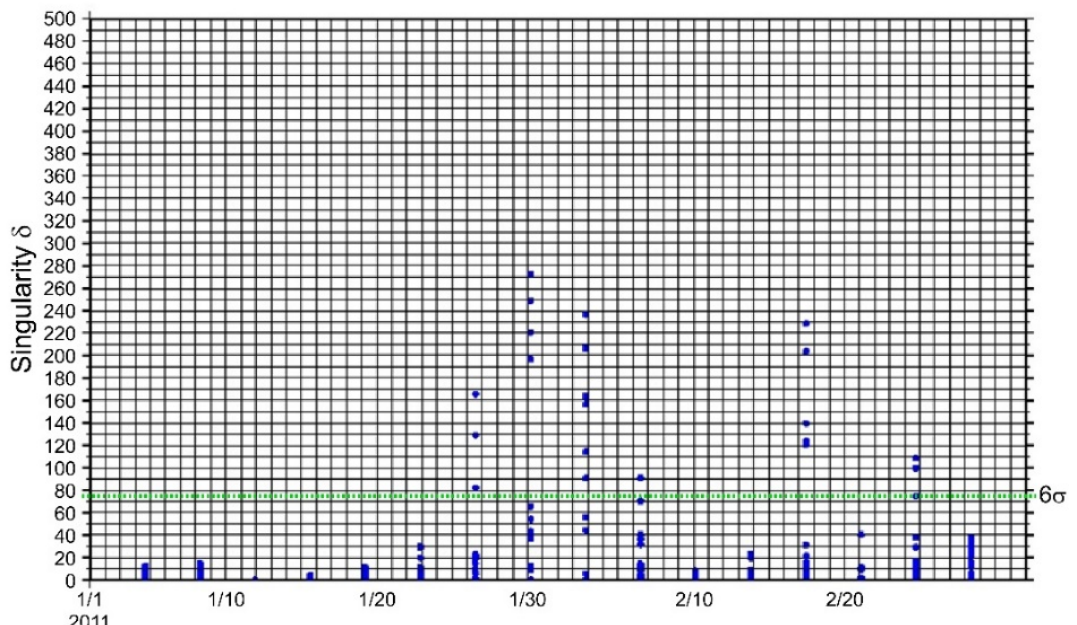

(a)

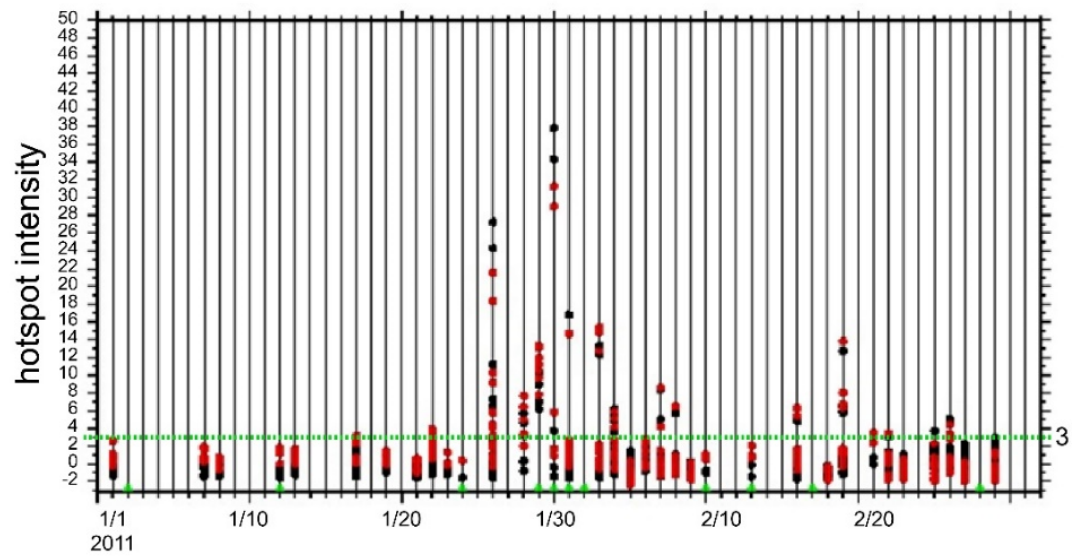

(b)

Figure 10. Temporal variation of singularity and $\mathrm{RST}_{\mathrm{VOLC}}$ at the summit crater of Shinmoedake during January-February 2011 in UT. (a) Singularity with this study for cloud detection; (b) hotspot intensity defined by RST VOLC.

To compare two methods, the method using singularity that we propose simplifies the concept of $\mathrm{RST}_{\text {VOLC }}$ in space and makes it complicated in cloud discrimination. It is important that the brightness temperature anomaly was detected near the crater on 26 January by two independent methods. It was one day before the eruption of lava at the crater confirmed by the SAR image on 27 January. 
This abnormal rise has also been confirmed by temperature analysis using Japanese MTSAT. A small eruption occurred at 1:19 on 26 January (LT) and at 14:49 (LT), the momentum of the volcanic plume increased and indicating a subplinian event. From around 16:00, inclinometer fluctuations indicating the contraction of magma chambers were recorded. There occurred three subplinian eruptions until 27 January (LT). Considering these facts, it can be said that it probably suggests that the magma effusion had started on the crater surface in the early morning of the 26 (around 01:00 LT), or that the precursor of magma effusion was detected.

In addition, the supply of magma to the crater from inclinometers, seismic records, and aerial observations is thought to have stopped in early February. From the aerial infrared photograph, the maximum period of heat from the crater is considered to be from the end of January to the beginning of February. This is consistent with the period of remarkable singularity. A dimple was confirmed in the center of the crater on 18 February, and it may be associated with increased thermal infrared activity in the middle of February. These results show the effectiveness of satellite infrared data for monitoring and predicting lava activity in volcanic lava activity.

Figure 11 shows a compilation of various data on the activity of Shinmoedake from January to February 2011. (a) shows the timing when the MODIS anomaly appeared and the timing when the eruption occurred [27-29]; (b) temporal change of lava dome volume obtained from satellite SAR image analysis [30,32]; (c) erupted lava volume estimated from tiltmeter data indicated in panel (f) [31]; (d) deflation rate of lava [31]; (e) variation of $10 \mathrm{~min}$ average value of the amplitude of seismometer [31]; (f) tiltmeter data near the Shinmoedake [31] and (g) schematic view of lava activity of the 2011 Shinmoedake activity [27-33].

From the inclinometer and GPS deformation data, magma was supplied to the main magma reservoir about $10 \mathrm{~km}$ northwest of Shinmoedake and 6-8 km underground. In January 2011, it moved to a magma chamber right below the crater of Shinmoedake, and the first phreatomagmatic explosion occurred on 19 January (LT). A petrological investigation confirmed that the first phreatomagmatic explosion on 19 January involved fresh magma. Supply of magma into the secondary chamber just below the crater continues, which leads to phreatomagmatic eruptions on 26-27 January and a sub-Plinian eruption on 27 January in LT. The satellite SAR image confirmed the lava effusion into the crater on 27 January and by eyes onboard aircraft on 28 January. Based on the tiltmeter and satellite SAR data, lava effusion into the crater went on through three sub-Plinian eruptions and the following continuous eruptions from 28 January to around 1 February. Then, the original crater was filled by lava. Based on the tiltmeter and satellite SAR data, lava effusion into the crater went on through three sub-Plinian eruptions and the following continuous eruptions from 28 January to around 1 February. Then, the original crater was filled by lava. MODIS images provide the first brightness temperature anomaly on 26 January, when was the before the first sub-Plinian eruption.

Since the erupted magma was gradually and slowly ascending from the deep magma chamber toward the crater in the conduit, it is considered that there are no apparent precursory changes in mechanical parameters regarding the 2011 Shinmoedake activity (small imminent precursory changes were registered just before the sub-Plinian eruptions eruption). In such a situation, it is quite difficult to use tiltmeters and microearthquakes to predict volcanic eruptions. However, satellite infrared observation may have the advantage of capturing thermal anomaly because magma heat is likely to be easily transferred to the surface from the magma body under the ground if a volcanic vent (conduit) is established. Infrared monitoring from satellites, in addition to ground-based mechanical sensors, is likely to be useful for monitoring and forecasting the volcanic eruption related to lava activity. 


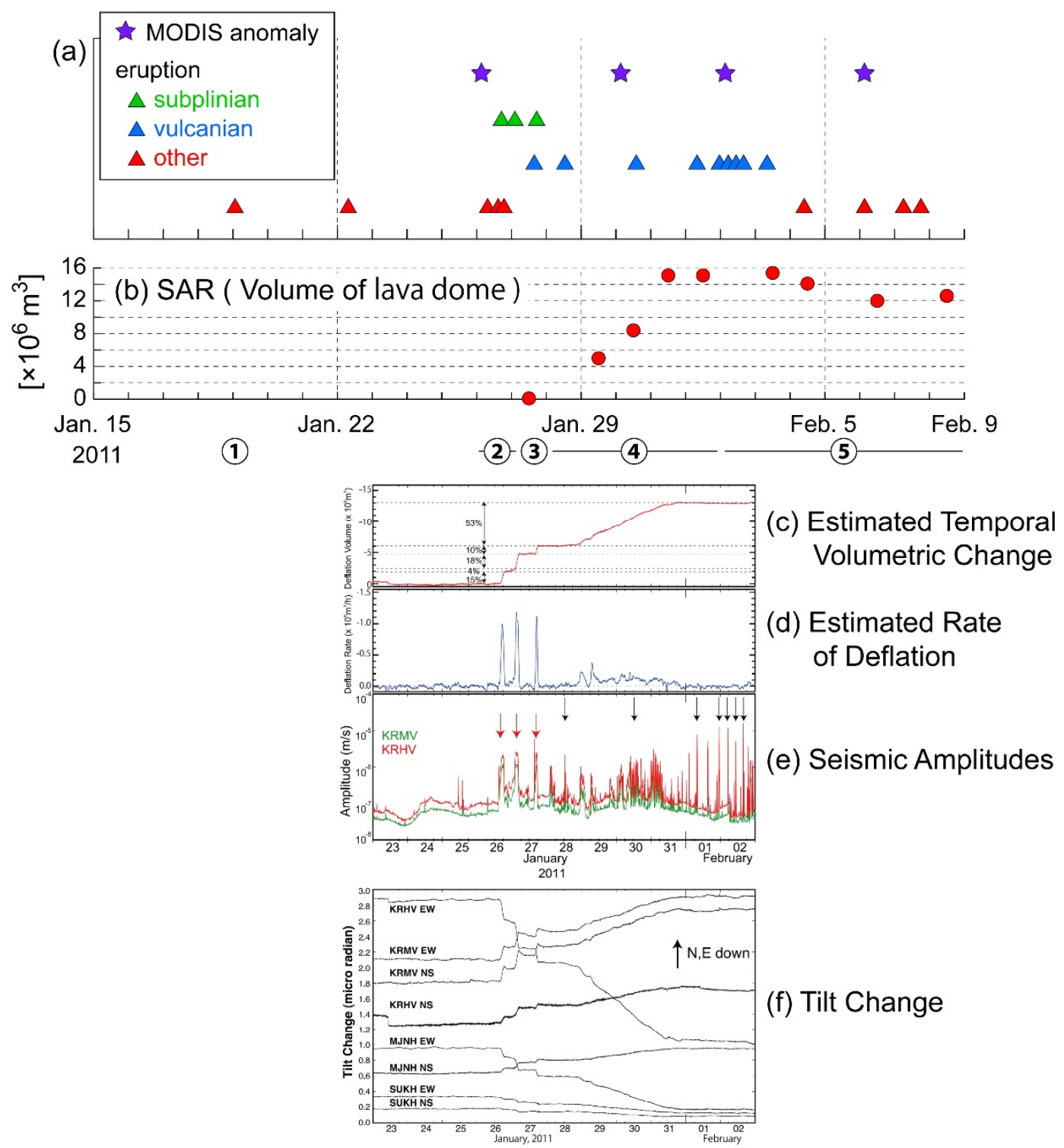

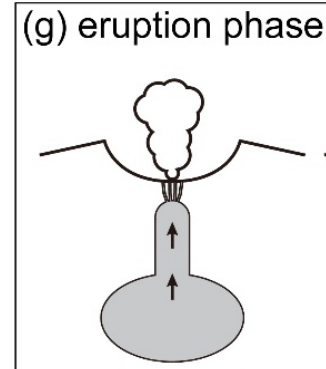

(1) January 19 eruption

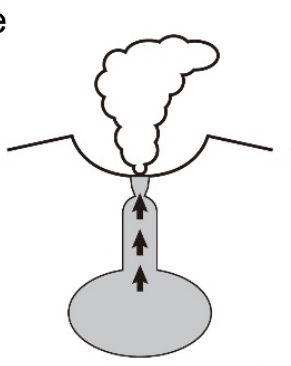

(2) January $26-27$ eruption

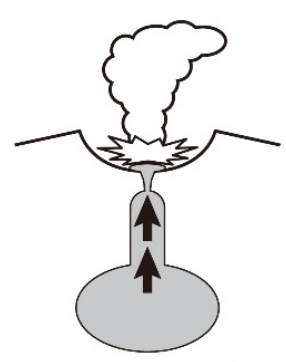

(3) January 27 $15 \mathrm{~h} 41 \mathrm{~m}$ eruption

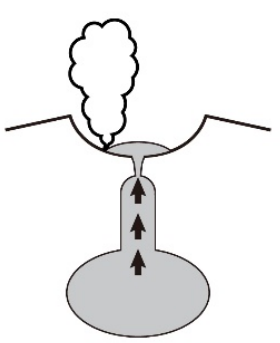

(4) January 28February 1 eruption

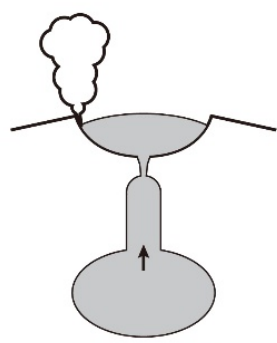

(5) February 2 eruption

Figure 11. Schematic view of the 2011 Shinmoedake volcanic activity from January to February 2011 in LT [27-33]. (a) Timing of MODIS anomaly and the timing and type of eruptions; (b) temporal variation of lava dome volume obtained from satellite SAR data; (c) erupted lava volume estimated by tiltmeter data shown in panel (f); (d) deflation rate of lava; (e) variation of $10 \mathrm{~min}$ average value of the amplitude of seismometer; (f) tiltmeter data near the Shinmoedake and (g) schematic view of lava activity of the 2011 Shinmoedake activity. Arrows in the magma indicate the intensity of the effusion rate. 


\section{Conclusions}

We proposed a cloud discrimination method applicable in Japan using MODIS nighttime data, monitored the singularity of the spatiotemporal correlation of surface temperature anomalies and investigated the possibility of detecting and monitoring lava activity in Shinmoedake. With the aim to detect lava eruption activity in 2011, nine years of data from 2003 to 2011 were analyzed. As a result, the first anomalous singularity in brightness temperature was detected on 26 January 2011. Moreover, the maximum value was detected on 30 January 2011 and the values showed larger ones until early February 2011. When the anomalous singularity appeared was the only period with the magma-related volcanic activity for Shinmoedake over the analyzed period of nine years.

Comparing comprehensively with satellite SAR images, aerial infrared images, photos of lava dome photo in the crater, tiltmeter data, seismograph data, etc., the period of large singularity values is consistent with the active period of lava effusion at the crater. In addition, the magnitude of specificity corresponds to the surface temperature of the crater. There is no contradiction that the anomaly in singularity disappears as the surface cools after February 2011.

The above facts indicate the effectiveness of the proposed singularity method to monitor the lava activity for Shinmoedake. Therefore, it is concluded that if cloud discrimination is realized with high accuracy, no spurious changes will come to arise, and no false detection of hotspot will be given.

In the future, it is necessary to apply this method to other volcanoes in the temperate zone and investigate its universal effectiveness. It is also necessary to develop applications such as volcanic monitoring in cold latitudes where snow and ice are covered.

In order to understand eruptive precursors and eruptive dynamics of volcanoes, analysis of the integration of multiparametric data observed in space and on the ground can be required. Continuous monitoring with high sampling by satellite also helps better monitor volcanic hazards. Since MODIS has a problem with the regression rate and its time resolution is not proper, it is necessary to develop an algorithm using meteorological satellites such as MTSAT (HIMAWARI-8/9) in this sense. Since thermal infrared rays are affected by clouds, it is also essential to develop a method based on microwaves.

Author Contributions: Conceptualization, K.H. and R.T.; methodology, K.H. and R.T.; software, R.T. and C.Y.; validation, K.H., R.T., N.G. and C.Y.; formal analysis, R.T. and C.Y.; writing-original draft preparation, R.T.; writing-review and editing, K.H. and N.G.; supervision, K.H.; funding acquisition, K.H. All authors have read and agreed to the published version of the manuscript.

Funding: This research was partly supported by a Grand-in-Aid for Scientific Research of the Japan Society for Promotion of Science (19403002, 26249060) and the National Institute of Information and Communication Technology (R \& D promotion funding for international joint research) and a joint research program in Center for Environmental Remote Sensing, Chiba University, Japan.

Acknowledgments: The authors would like to express thanks to the Goddard Space Flight Center, the National Aeronautics and Space Administration for providing MODIS data. LiDAR data were provided by courtesy of AD-Net (https://www-lidar.nies.go.jp/AD-Net), the National Institute for Environmental Studies, Japan. This research was partly supported by a Grand-in-Aid for Scientific Research of the Japan Society for Promotion of Science $(19403002,26249060)$ and the National Institute of Information and Communication Technology (R \& D promotion funding for international joint research) and a joint research program of Center for Environmental Remote Sensing, Chiba University, Japan.

Conflicts of Interest: The authors declare no conflict of interest.

\section{Appendix A}

Appendix A provides some pictures and figures reported by JMA [29]. Figures A1 and A2 indicate aerial photos of the summit crater of Shinmoedake and aerial thermal infrared images of the crater, respectively. Figure A1 gives the change of shape and lava effusion in the crater with volcanic activity. Figure A2 supplies the direct ground truth of MODIS analysis. Figure A3 shows satellite SAR images to give topological changes in the summit crater. 


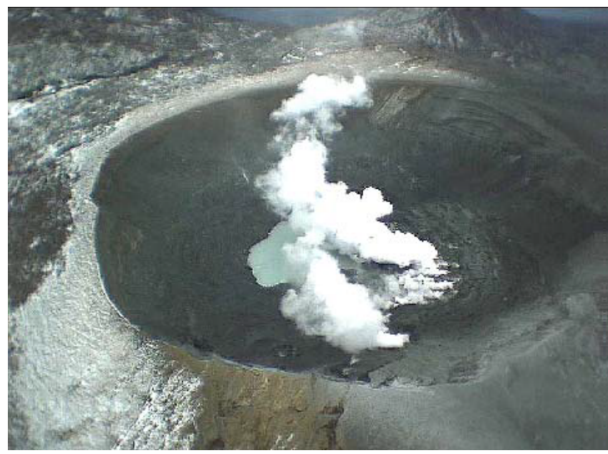

(a) 10:56 on January 21, 2011 (LT)

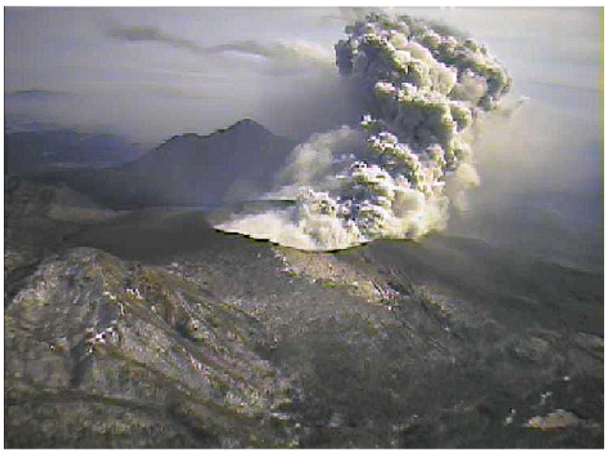

(c) 14:15 on January 27, 2011 (LT)

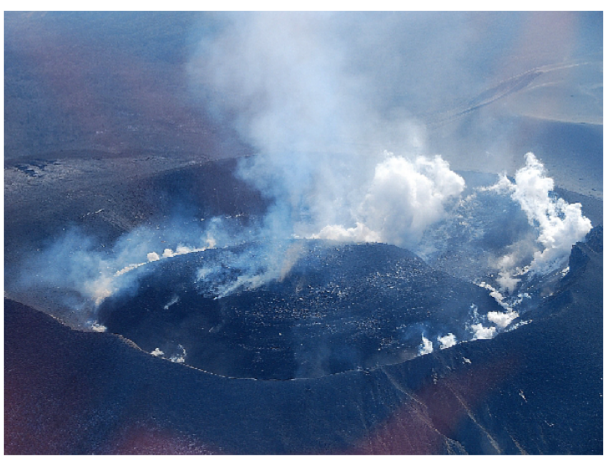

(e) 10:06 on February 1, 2011 (LT)

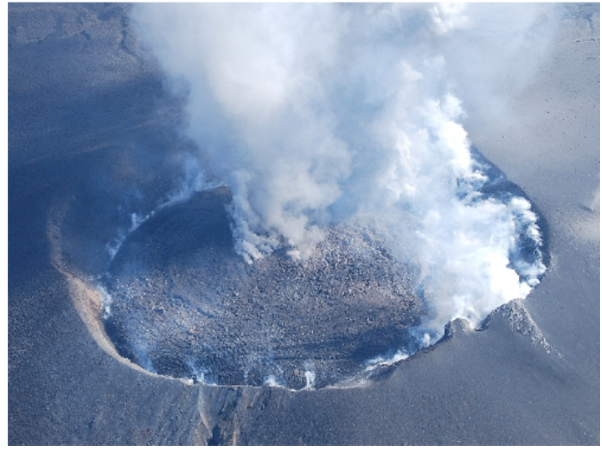

(g) 11:04 on February 3, 2011 (LT)

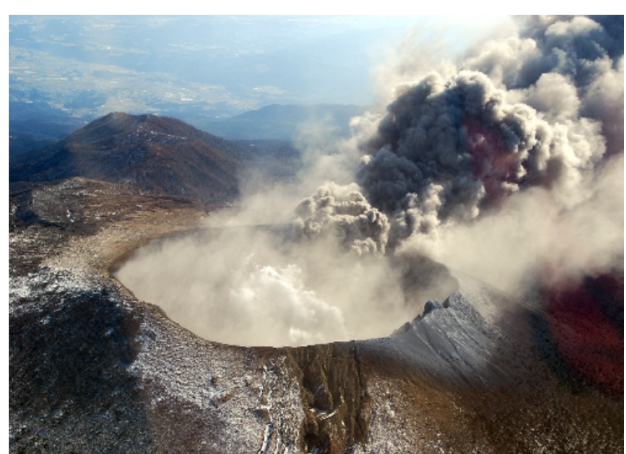

(b) 10:42 on January 26, 2011 (LT)

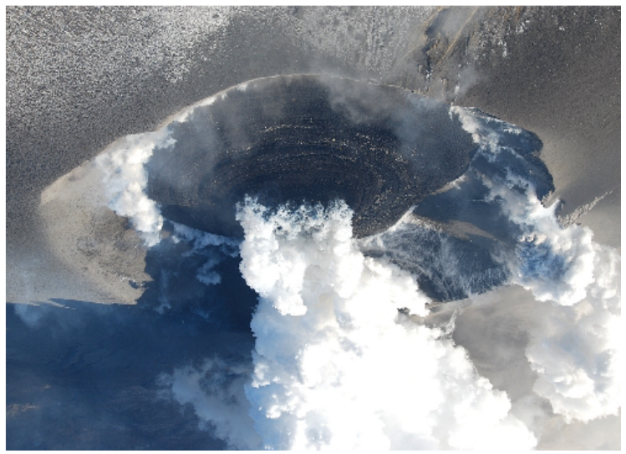

(d) 13:45 on January 31, 2011 (LT)

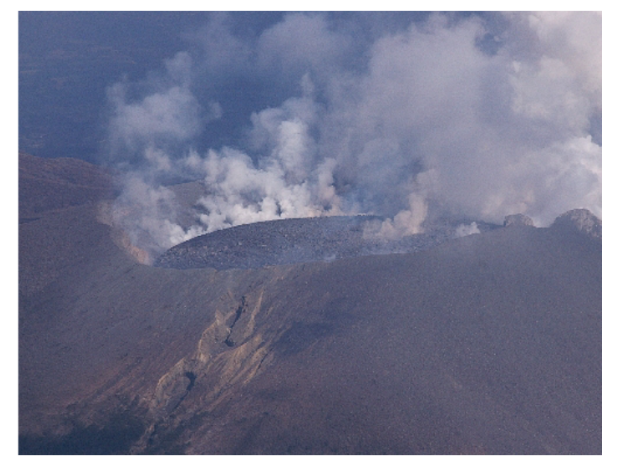

(f) 14:28 on February 2, 2011 (LT)

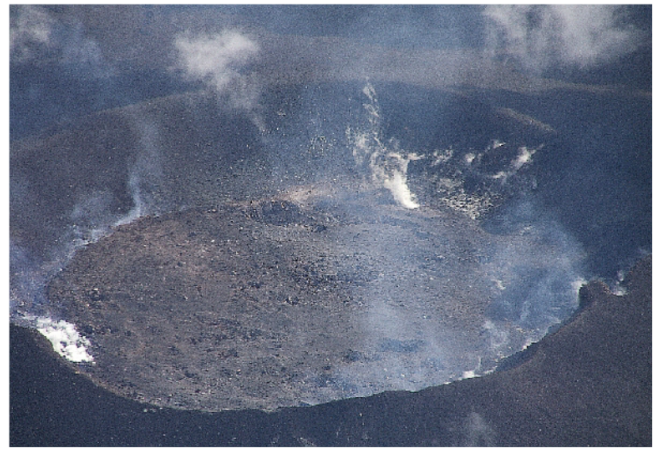

(h) 11:05 on February 25, 2011 (LT)

Figure A1. Cont. 


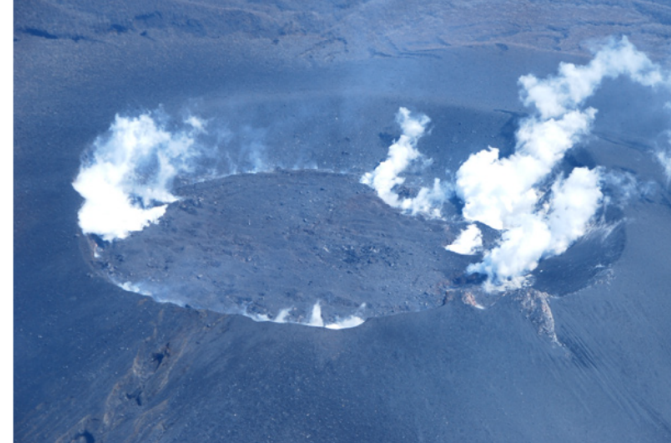

(i) 12:00 on March 22, 2011 (LT)

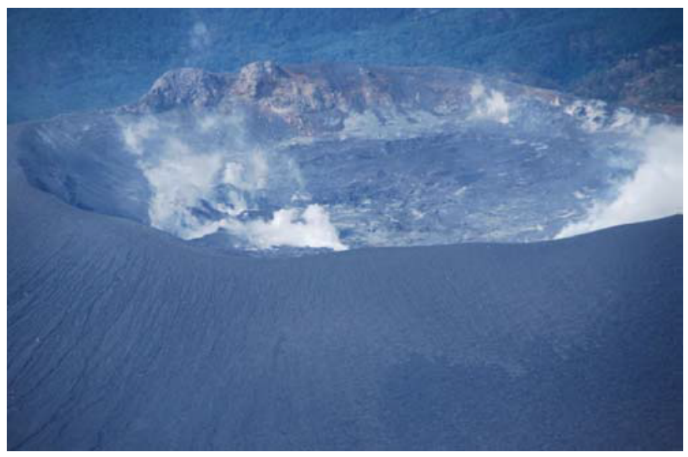

(k) 9:47 on September 22, 2011 (LT)

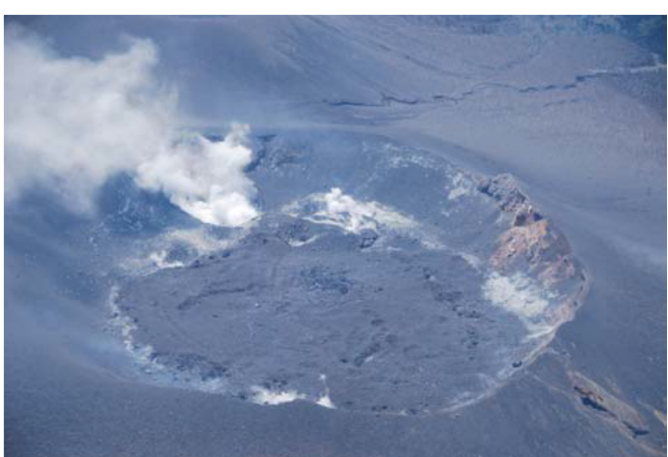

(j) 10:52 on March 11, 2011 (LT)

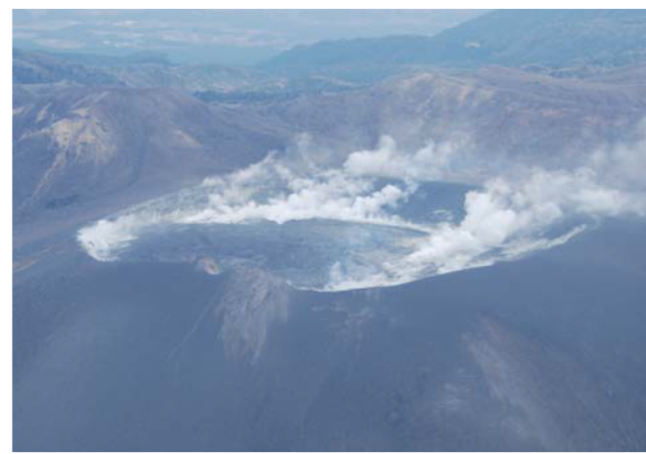

(1) 10:31 on December 21, 2011 (LT)

Figure A1. Aerial images of the summit crater of Shinmoedake from 21 January 2011 to 21 December 2011 (after JMA report [29]). On 19 January, there was a small eruption, probably due to a magmatophreatic explosion. The condition of the plume was unknown due to bad weather, but ashfall was confirmed from Shinmoedake in the southeast direction (a) 21 January: After magmatophreatic explosion, it was confirmed that the fumaroles, formed by the eruption on 27 May 2010, expanded, the ejecta was thickly accumulated in the crater and the cinder was scattered in the crater. Clear traces of ashfall were confirmed around the Shinmoedake crater and in the southeast direction from the crater. (b) The photo of the crater after the small eruption at 7:31 but before the magmatic explosion at 14:49 on 26 January. The plume was flowing to the southeast. The eruption at 07:31 shifted to the magmatic eruption around 14:49. Due to the magmatic eruption, small volcanic blocks (volcanic debris) with a diameter of $7-8 \mathrm{~cm}$ about $3 \mathrm{~km}$ southeast of Shinmoedake crater and a diameter of $4-6 \mathrm{~cm}$ about $7 \mathrm{~km}$ southeast of the crater were confirmed. This eruption continued until February 7. (c) The first explosive eruption occurred on 27 January. The plume was flowing to the southeast. (d) Accumulation of discharged lava in the crater on 31 January. It was about $500 \mathrm{~m}$ in diameter and the top of the lava dome reached near the crater edge; (e) Accumulation of discharged lava in the crater on 1 February. It was about $500 \mathrm{~m}$ in diameter and a part of the top of the lava dome was slightly lower than that of yesterday; (f) Accumulation of ejected lava in the crater on 2 February: Expanded to a diameter of $600 \mathrm{~m}$. The top of the lava dome turned to be flat; (g)-(1) There was no particular change in the size and shape of the lava accumulated in the crater and the surrounding fumarole and the plume was rising from the north and east sides of the lava. 


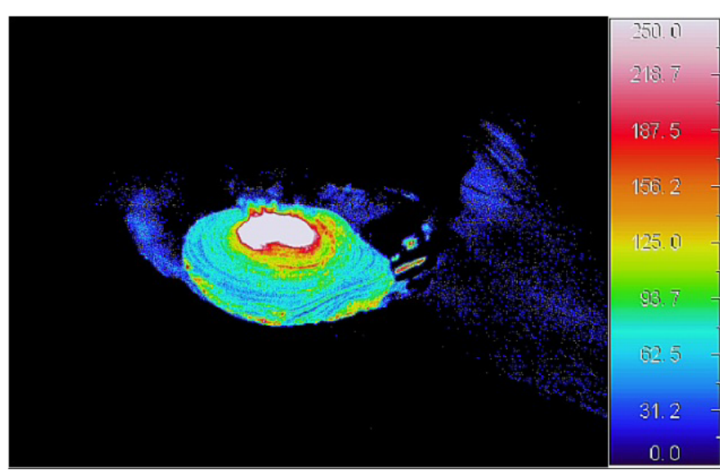

(a) January 31, 2011 (LT)

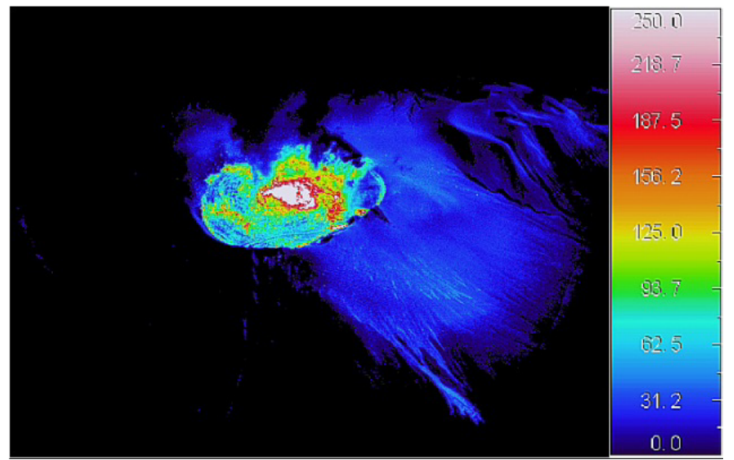

(c) February 3, 2011 (LT)

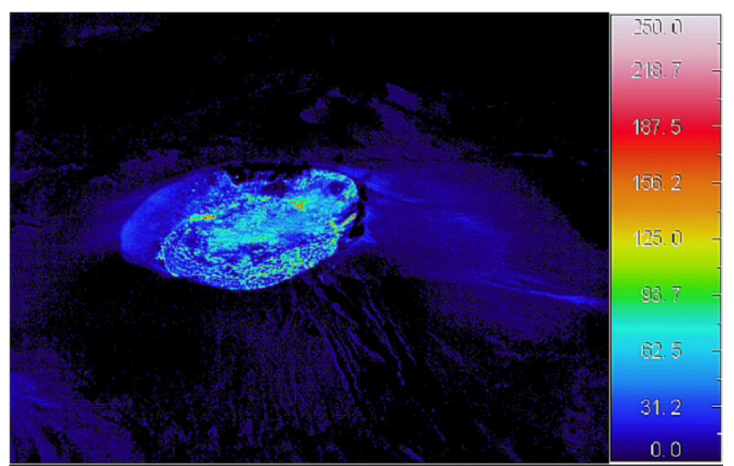

(e) February 18, 2011 (LT)

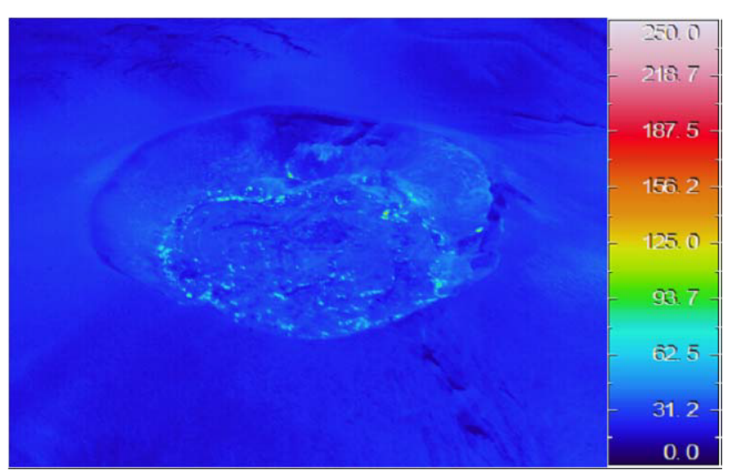

(g) May 31, 2011 (LT)

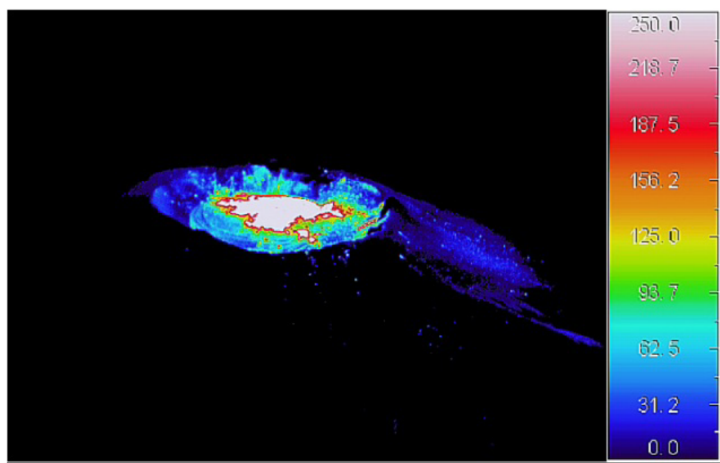

(b) February 1, 2011 (LT)

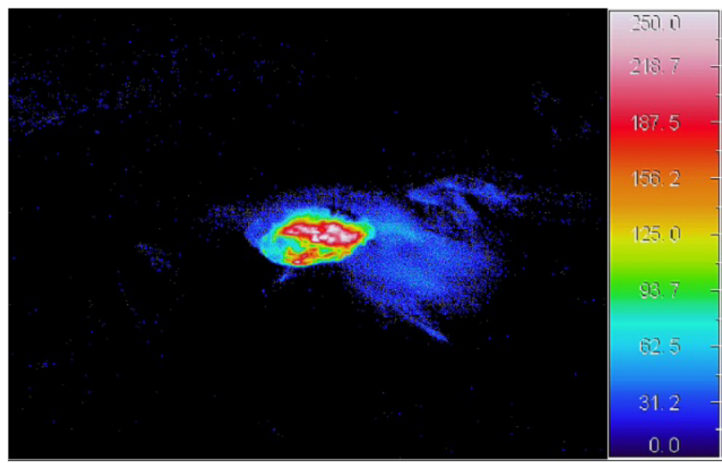

(d) February 7, 2011 (LT)

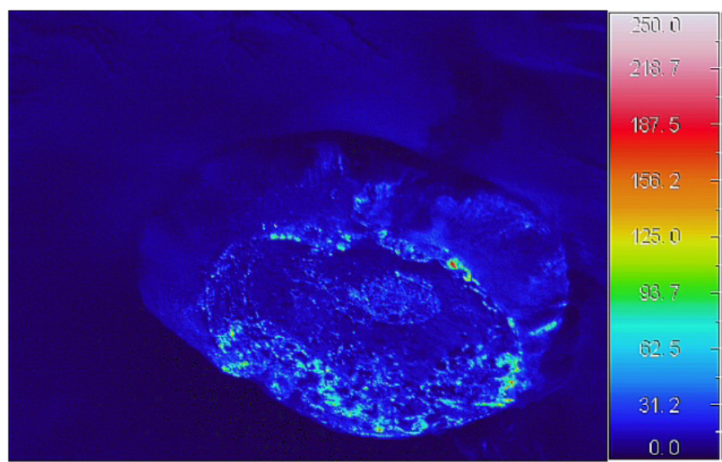

(f) March 7, 2011 (LT)

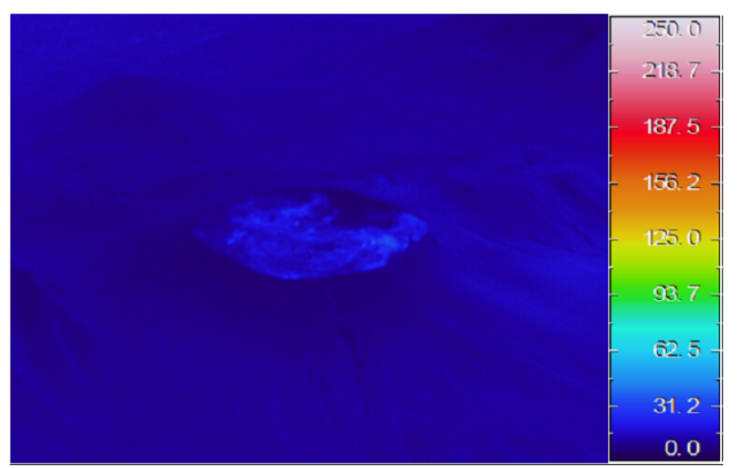

(h) September 22, 2011 (LT)

Figure A2. Aerial thermal infrared images of the summit crater of Shinmoedake (after JMA report [29]). (a) 31 January, (b) 1 February (c) 2 February, (d) 3 February, (e) 18 February (f) 7 March, (g) 31 May, (h) 22 September. The central part of the discharged lava was very hot at first, but the surface temperature of the lava gradually decreased. 


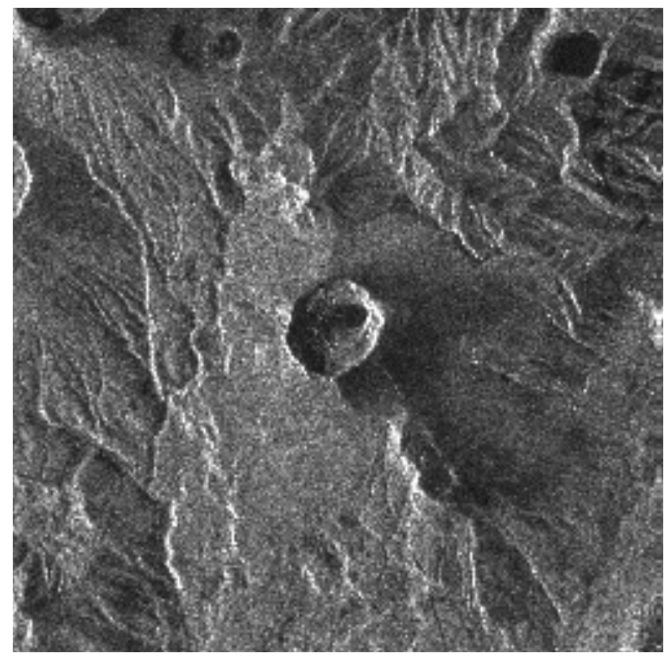

(a) January 2, 2010 (LT)

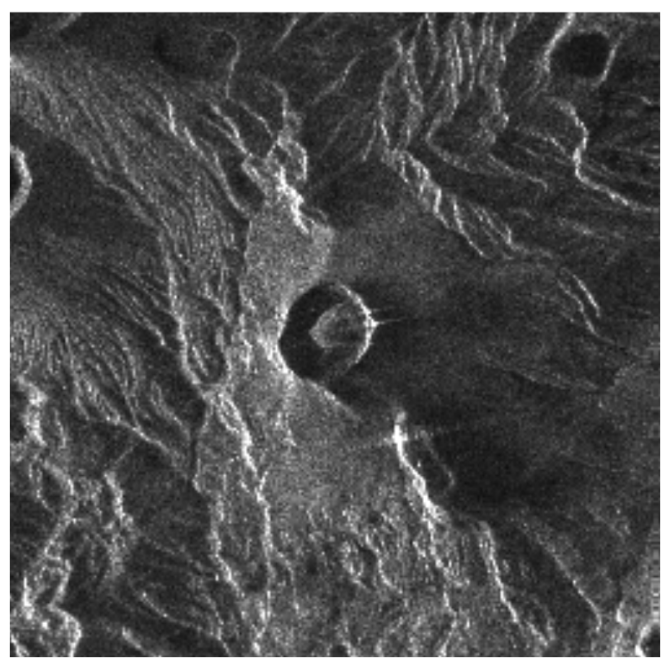

(c) January 29, 2011 (LT)

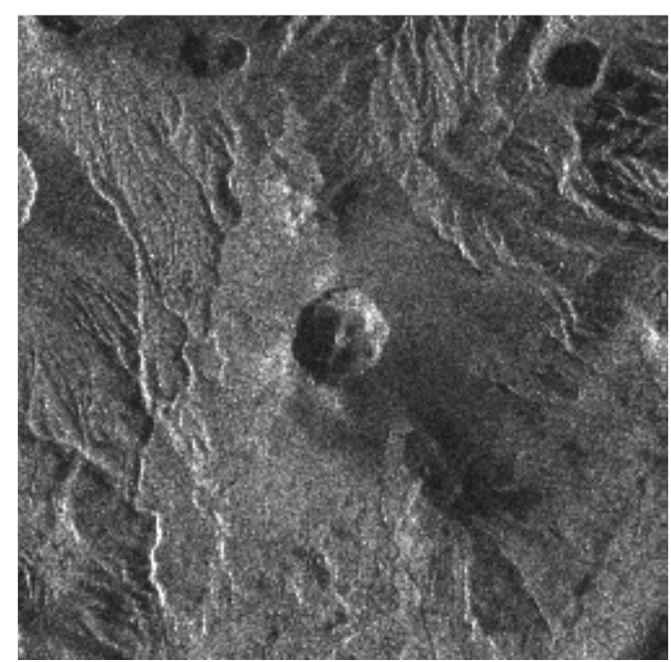

(b) January 27, 2011 (LT)

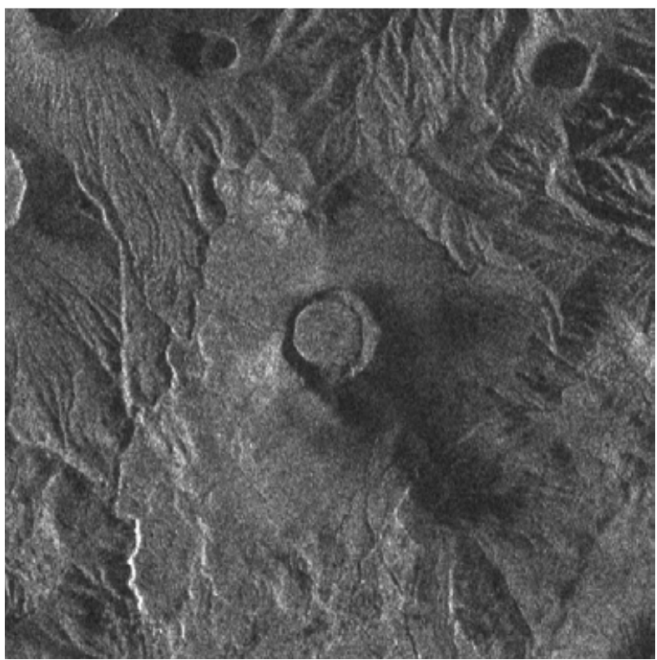

(d) February 1, 2011 (LT)

Figure A3. ALOS/PALSAR images of the summit crater of Shinmoedake (after JMA (Japan Meteorological Agency) report [29]). ALOS means Advanced Land Observing Satellite and the PALSAR aboard ALOS is Phased Array type L-band Synthetic Aperture Radar (SAR) sensor. (a) 2 January 2010. A photo about one year before the 2011 eruption. The existence of the crater lake can be confirmed; (b) 27 January 2011. The existence of a small bulge or a small rise in the center of the crater can be confirmed; (c) 29 January 2011. Discharged lava grew and a lava dome can be confirmed in the center of the crater; (d) 1 February 2011. Discharged lava fills the crater and the diameter of lava is about $500 \mathrm{~m}$.

\section{References}

1. Dehn, J.; Dean, K.G.; Engle, K. Thermal monitoring of North Pacific volcanoes from space. Geology 2000, 28, 755-758. [CrossRef]

2. Wright, R.; Flynn, L.; Garbeil, H.; Harris, A.; Pilger, E. Automated volcanic eruption detection using MODIS. Remote Sens. Environ. 2002, 82, 135-155. [CrossRef]

3. Pergola, N.; Tramutoli, V.; Scaffidi, I.; Lacava, T.; Marchese, F. Improving volcanic ash cloud detection by robust satellite technique. Remote Sens. Environ. 2004, 90, 1-22. [CrossRef]

4. Pergola, N.; Marchese, F.; Tramutoli, V. Automated detection if thermal features of active volcanoes by means of infrared AVHRR records. Remote Sens. Environ. 2004, 93, 311-327. [CrossRef]

5. Rothery, D.A.; Coppola, D.; Saunders, C. Analysis of volcanic activity patterns using MODIS thermal alerts. Bull. Volcanol. 2005, 67, 539-556. [CrossRef] 
6. Kaneko, T.; Takasaki, K.; Yasuda, A.; Aoki, Y. Thermal surveillance of the Asama 2004-2005 activity using MODIS nighttime infrared images. Bull. Volcanol. Soc. Jpn. 2006, 51, $273-282$.

7. Pieri, D.; Abrams, M. ASTER watches the world's volcanoes: A new paradigm for volcanological observations from orbit. J. Volcanol. Geotherm. Res. 2004, 135, 13-28. [CrossRef]

8. Wright, R.; Pilger, E. Radiant flux from Earth's subaerially erupting volcanoes. Int. J. Remote Sens. 2008, 29, 6443-6466. [CrossRef]

9. Noguchi, T.; Ohno, N.; Hattori, K.; Oyama, K. Detection of thermal changes associated with volcanic activity and discrimination of faint changes from MODIS data. J. Asian Earth Sci. 2011, 41, 467-475. [CrossRef]

10. Marchese, F.; Lacava, T.; Pergola, N.; Hattori, K.; Miraglia, E.; Tramutoli, V. Inferring phases of thermal unrest at Mt. Asama (Japan) from infrared satellite observations. J. Volcanol. Geotherm. Res. 2012, 237-238, 10-18. [CrossRef]

11. Kaneko, T.; Takasaki, K.; Maeno, F.; Wooster, M.J.; Yasuda, A. Himawari-8 infrared observations of the June-August 2015 Mt Raung eruption, Indonesia. Earth Planets Space 2018, 70, 1-9. [CrossRef]

12. Coppola, D.; Laiolo, M.; Cigolini, C.; Delle Donne, D.; Ripepe, M. Enhanced volcanic hotspot detection using MODIS IR data: Results from the MIROVA system. Geol. Soc. Lond. Spec. Publ. 2015, 426, 181-205. [CrossRef]

13. Pergola, N.; Coviello, I.; Filizzola, C.; Lacava, T.; Marchese, F.; Paciello, R.; Tramutoli, V. A review of rstvolc, an original algorithm for automatic detection and near-real-time monitoring of volcanic hotspots from space. Geol. Soc. Lond. Spec. Publ. 2015, 426, 55-72. [CrossRef]

14. Valade, S.; Ley, A.; Massimetti, F.; D’Hondi, O.; Laiolo, M.; Coppola, D.; Loibl, D.; Helwich, O.; Walter, R. Towards global volcano monitoring using multisensor sentinel missions and artificial intelligence: The MOUNTS monitoring system. Remote Sens. 2019, 11, 1528. [CrossRef]

15. Ganci, G.; Vicari, A.; Fortuna, L.; Del Negro, C. The HOTSAT volcano monitoring system based on combined use of SEVIRI and MODIS multispectral data. Ann. Geophys. 2011, 54, 544-550.

16. Gouhier, M.; Guéhenneux, Y.; Labazuy, P.; Cacault, P.; Decriem, J.; Rivet, S. HOTVOLC: A web-based monitoring system for volcanic hot spots. Geol. Soc. Lond. Spec. Publ. 2015, 426, 223-241. [CrossRef]

17. Lombardo, V. AVHotRR: Near-real time routine for volcano monitoring using IR satellite data. Geol. Soc. Lond. Spec. Publ. 2015, 426, 73-92. [CrossRef]

18. Oppenheimer, C. Lava flow cooling estimated from Landsat thematic mapper infrared data: The Lonquimay eruption (Chile, 1989). J. Geophys. Res. Solid Earth 1991, 96, 21865-21878. [CrossRef]

19. Marchese, F.; Genzano, N.; Neri, M.; Falconieri, A.; Mazzeo, G.; Pergola, N. A multi-channel algorithm for mapping volcanic thermal anomalies by means of sentinel-2 MSI and Landsat-8 OLI data. Remote Sens. 2019, 11, 2876. [CrossRef]

20. Ramsey, M.S.; Flynn, I.T. The spatial and spectral resolution of ASTER infrared image data: A paradigm shift in volcanological remote sensing. Remote Sens. 2020, 12, 738. [CrossRef]

21. Li, J.; Menzel, W.P.; Yang, Z.; Frey, R.A.; Ackerman, S.A. High-spatial-resolution surface and cloud-type classification from MODIS multispectral band measurements. J. Appl. Meteorol. 2003, 42, 204-226. [CrossRef]

22. Li, J.; Menzel, W.P.; Sun, F.; Schmit, T.J.; Gurka, J. AIRS subpixel cloud characterization using MODIS cloud products. J. Appl. Meteorol. 2004, 43, 1083-1094. [CrossRef]

23. Ackerman, S.A.; Strabala, K.I.; Menzel, W.P.; Frey, R.A.; Moeller, C.C.; Gumley, L.E. Discriminating clear sky from clouds with MODIS. J. Geophys. Res. 1998, 103, 32141-32157. [CrossRef]

24. Frey, R.A.; Ackerman, S.A.; Liu, Y.; Strabala, K.I.; Zhang, H.; Key, J.R.; Wang, X. Cloud detection with MODIS. Part I: Improvements in the MODIS cloud mask for collection 5. J. Atmos. Ocean. Technol. 2008, 25, 1057-1072. [CrossRef]

25. Imura, R.; Kobayashi, T. Eruptions of shinmoedake volcano, kirishima volcano group, in the last 300 years. Bull. Volcanol. Soc. Jpn. 1991, 36, 135-148. (In Japanese with English abstract).

26. Tsutsui, M.; Tomita, K.; Kobayashi, T. Fumarolic activity since December 2003 and volcanic activity during the Meiji and Taisho eras (1880-1923) of Ohachi volcano, kishirima volcano group, Southern Kyushu, Japan. Bull. Volcanol. Soc. Jpn. 2005, 50, 475-489. (In Japanese with English abstract).

27. Kato, K.; Yamasato, H. The 2011 eruptive activity of Shinmoedake volcano, Kirishimayama, Kyushu, Japan-Overview of activity and volcanic alert level of the Japan meteorological agency-. Earth Planets Space 2013, 65, 489-504. [CrossRef] 
28. Fukuoka District Meteorological Observatory and Kagoshima Local Meteorological Observatory. The 2011 eruptive activities of Shinmoedake volcano, Kirishimayama, Kyushu, Japan. Q. J. Seismol. 2013, 77, 65-96, (In Japanese with English abstract).

29. JMA (Japan Meteorological Agency). Voclanic activity of Kirishimayama volcano-February 2011-May 2011. In Report of Coordinating Committee for Prediction of Volcanic Eruption; JMA: Tokyo, Japan, 2012; Volume 109, pp. 139-167. (In Japanese)

30. Ando, S. Change in Shinmoedake crater of Kirishimayama volcano observed by ALOS/DAICHI. Q. J. Seismol. 2013, 77, 97-110, (In Japanese with English abstract).

31. Ueda, H.; Kozono, T.; Fujita, E.; Kohno, Y.; Nagai, M.; Miyagi, Y.; Tanada, T. Crustal deformation associated with the 2011 Shinmoe-dake eruption as observed by tiltmeters and GPS. Earth Planets Space 2013, 65, 517-525. [CrossRef]

32. Ozawa, T.; Kozono, T. Temporal variation of the Shinmoe-dake crater in the 2011 eruption revealed by spaceborne SAR observations. Earth Planets Space 2013, 65, 527-537. [CrossRef]

33. Nakada, S.; Nagai, Y.; Kaneko, T.; Suzuki, Y.; Maeno, F. The outline of the 2011 eruption at Shinmoe-dake (Kirishima), Japan. Earth Planets Space 2013, 65, 475-486. [CrossRef]

34. Sugimoto, N.; Matsui, I.; Shimizu, A.; Nishizawa, T.; Hara, Y.; Xie, C.; Uno, I.; Yumimoto, K.; Wang, Z.; Yoon, S.-C. Lidar network observations of tropospheric aerosols. SPIE 2008, 7153. [CrossRef]

35. Sugimoto, N.; Nishizawa, T.; Shimizu, A.; Matsui, I.; Jin, Y.; Higurashi, A.; Uno, I.; Hara, Y.; Yumimoto, K.; Kudo, R. Continuous observations of atmospheric aerosols across Ease Asia. SPIE Newsroom 2015. [CrossRef]

36. Takano, T.; Maeda, T. Discrimination of local and faint changes from satellite borne microwave-radiometer data. IEEE Trans. Geosci. Remote Sens. 2008, 46, 2684-2691.

37. The Asian Dust and Aerosol Lidar Observation Network (AD-Net). NIES (National Institute for Environmental Studies): Tsukuba, Japan. 2016. Available online: https://www-lidar.nies.go.jp/AD-Net/ (accessed on 1 August 2020).

38. Harris, A.J.L.; De Groeve, T.; Garel, F.; Carn, S.A. (Eds.) Detecting, Modelling and Responding to Effusive Eruptions; Geological Society of London: London, UK, 2016; Volume 426.

39. Kozono, T.; Ueda, H.; Ozawa, T.; Koyaguchi, T.; Fujita, E.; Tomiya, A.; Suzuki, Y. Magma discharge variations during the 2011 eruptions of Shinmoe-dake volcano, Japan, revealed by geodetic and satellite observations. Bull. Volcanol. 2013, 75, 695. [CrossRef]

40. Yamazaki, K.; Teraishi, M.; Ishihara, K.; Komatsu, S.; Kato, K. Subtle changes in strain prior to sub-plinian eruptions recorded by vault-housed extensometers during the 2011 activity at Shinmoe-dake, Kirishima volcano, Japan. Earth Planets Space 2013, 65, 1491-1499. [CrossRef]

41. Miyabuchi, Y.; Hanada, D.; Niimi, H.; Kobayashi, T. Stratigraphy, grain-size and component characteristics of the 2011 Shinmoedake eruption deposits, Kirishima volcano, Japan. J. Volcanol. Geotherm. Res. 2013, 258, 31-46. [CrossRef]

42. Tramutoli, V. Robust AVHRR techniques (RAT) for environmental monitoring: Theory and applications. In Earth Surface Remote Sensing II, Proceedings of SPIE; Zilioli, E., Ed.; SPIE Press: Bellingham, WA, USA, 1998; Volume 3496, pp. 101-113.

43. Tramutoli, V. Robust satellite techniques (RST) for natural and environmental hazards monitoring and mitigation: Theory and applications. In Proceedings of the 2007 International Workshop on the Analysis of Multi-Temporal Remote Sensing Images, Leuven, Belgium, 18-20 July 2007; IEEE: Piscataway, NJ, USA, 2007; pp. 1-6. [CrossRef]

44. Marchese, F.; Falconieri, A.; Pergola, N.; Tramutoli, V. A retrospective analysis of the Shinmoedake (Japan) eruption of 26-27 January 2011 by means of Japanese geostationary satellite data. J. Volcanol. Geotherm. Res. 2014, 269, 1-13. [CrossRef]

(C) 2020 by the authors. Licensee MDPI, Basel, Switzerland. This article is an open access article distributed under the terms and conditions of the Creative Commons Attribution (CC BY) license (http://creativecommons.org/licenses/by/4.0/). 